\title{
A Positive Autoregulatory BDNF Feedback Loop via C/EBP $\beta$ Mediates Hippocampal Memory Consolidation
}

\author{
(1) Dhananjay Bambah-Mukku, ${ }^{1,2}$ Alessio Travaglia, ${ }^{1 \star}$ Dillon Y. Chen, ${ }^{2 \star}$ Gabriella Pollonini, ${ }^{1}$ and Cristina M. Alberini ${ }^{1}$ \\ ${ }^{1}$ Center for Neural Science, New York University, New York, New York 10003 and ${ }^{2}$ Department of Neuroscience and Friedman Brain Institute, Icahn School \\ of Medicine at Mount Sinai, New York, New York 10029
}

Little is known about the temporal progression and regulation of the mechanisms underlying memory consolidation. Brain-derivedneurotrophic-factor (BDNF) has been shown to mediate the maintenance of memory consolidation, but the mechanisms of this regulation remain unclear. Using inhibitory avoidance (IA) in rats, here we show that a hippocampal BDNF-positive autoregulatory feedback loop via CCAAT-enhancer binding protein $\beta(\mathrm{C} / \mathrm{EBP} \beta)$ is necessary to mediate memory consolidation. At training, a very rapid, learninginduced requirement of BDNF accompanied by rapid de novo translation controls the induction of a persistent activation of cAMPresponse element binding-protein (CREB) and C/EBP $\beta$ expression. The latter, in turn, controls an increase in expression of $b d n f$ exon $I V$ transcripts and BDNF protein, both of which are necessary and, together with the initial BDNF requirement, mediate memory consolidation. The autoregulatory loop terminates by $48 \mathrm{~h}$ after training with decreased C/EBP $\beta$ and pCREB and increased methyl-CpG binding protein-2, histone-deacetylase-2, and switch-independent-3a binding at the bdnf exon IV promoter.

Key words: BDNF; C/EBP; consolidation; hippocampus; memory; memory persistence

\section{Introduction}

Long-term memories are initially labile, but over time become insensitive to disruption through a process known as consolidation (Davis and Squire, 1984; Dudai, 2004; Alberini, 2009). Widely studied pharmacological compounds that disrupt consolidation are protein and RNA synthesis inhibitors, which have provided evidence that de novo transcription and translation are evolutionarily conserved mechanisms of memory consolidation. Numerous investigations, especially based on genetic mutations or deletions, have thus focused on the identification of which genes and proteins mediate long-term memory formation. Although the nature of several genes and proteins necessary for memory formation have been established, the temporal progression of the learning-dependent de novo protein synthesis and of molecular events that accompany the progression of memory consolidation remains poorly characterized. This characterization is critical for understanding the progression of the functional mechanisms of memory consolidation and storage, which provides important information for how/when to intervene to strengthen or weaken memories.

Received Jan. 23, 2014; revised June 27, 2014; accepted July 29, 2014

Author contributions: D.B.-M. and C.M.A. designed research; D.B.-M., A.T., D.Y.C., and G.P. performed research; D.B.-M., A.T., D.Y.C., G.P., and C.M.A. analyzed data; D.B.-M. and C.M.A. wrote the paper.

This work was supported by grants from the U.S. National Institutes of Health (R01-MH065635 and R37MH065635 to C.M.A. and F31-MH816213 to D.Y.C.). We thank Ja Wook Koo and Victoria Swiss for technical support.

${ }^{*}$ A.T. and D.Y.C. contributed equally to this work

The authors declare no competing financial interests.

Correspondence should be addressed to Cristina M. Alberini, Center for Neural Science, New York University, 4 Washington Place, New York, NY, 10003. E-mail: ca60@nyu.edu.

DOI:10.1523/JNEUROSCI.0324-14.2014

Copyright $\odot 2014$ the authors $\quad 0270-6474 / 14 / 3412547-13 \$ 15.00 / 0$
Most early studies on memory consolidation led to the belief that de novo gene expression is required only for a very brief temporal window, on the order of $1-2 \mathrm{~h}(\mathrm{~h})$ after training. However, in the last decade several reports have indicated that training activates hippocampal molecular changes whose progression is critical for a day or longer. These changes include redistribution of glutamate receptors, activation of protein kinases, and gene expression regulation (Taubenfeld et al., 2001a,b; Katche et al., 2013). In particular, in the hippocampus of rats trained with inhibitory avoidance (IA), the critical role of the evolutionarily conserved CREB-C/EBP pathway begins immediately after training and progresses for $>20 \mathrm{~h}$. In fact, IA memory formation is accompanied by a significant increase in CREB activation (phosphorylation of Ser133, pCREB; Taubenfeld et al., 2001a,b), which lasts for $>20 \mathrm{~h}$ after training and requires the expression of the CREB-downstream target gene $\mathrm{C} / \mathrm{EBP} \beta$ for $>24$ h post training (Taubenfeld et al., 2001a). These data imply that de novo protein synthesis critical for memory consolidation must still take place $24 \mathrm{~h}$ after IA training (Alberini, 2009). In agreement, anisomycin injected into the hippocampus $12 \mathrm{~h}$ after step-down IA training leaves memory intact at $2 \mathrm{~d}$ after training, but this memory decays at $7 \mathrm{~d}$ after training, indicating that de novo protein synthesis $\sim 12$ $\mathrm{h}$ after training is essential for memory persistence (Bekinschtein et al., 2007a). Furthermore, the expression of hippocampal BDNF is increased at $12 \mathrm{~h}$ after IA training, and blocking hippocampal BDNF $12 \mathrm{~h}$ after training blocks memory persistence. Finally, coinjection of recombinant BDNF into the hippocampus rescues the memory deficit caused by anisomycin injection at $12 \mathrm{~h}$ after training (Bekinschtein et al., 2008), indicating that BDNF is critical for memory persistence (Medina et al., 2008). Despite this knowledge, the molecular mechanisms that mediate this temporally extended requirement of protein synthesis and 
BDNF on memory persistence and its regulation are not known. Furthermore, it is not known for how long the fragile phase of memory consolidation continues and which mechanisms end the process. In this study, we asked precisely these questions: Are the extended gene expression and BDNF requirements linear processes? Are they connected? If so, how? And, how are they terminated? We used rat IA to elucidate the temporal evolution of gene expression and BDNF-dependent mechanisms required for induction, progression, and completion of memory consolidation.

\section{Materials and Methods}

Animals. Adult male, Long-Evans rats weighing between 200 and $250 \mathrm{~g}$ served as subjects in all experiments. Animals were all singly housed and maintained on a $12 \mathrm{~h}$ light/dark cycle. Experiments were performed during the light cycle. All rats were allowed ad libitum access to food and water and were handled for $3 \mathrm{~min}$ per day for $5 \mathrm{~d}$ before any procedure. All protocols complied with the NIH Guide for the Care and Use of Laboratory Animals and were approved by the Mt. Sinai School of Medicine and New York University Animal Care Committees.

Cannulae implants and hippocampal injections. Rats were anesthetized with ketamine (65 mg/kg, i.p.) and xylazine (7.5 mg/kg, i.p.), and stainless steel guide cannulae (22 gauge) were stereotactically implanted to bilaterally target the hippocampus ( $4.0 \mathrm{~mm}$ posterior to the bregma, 2.6 $\mathrm{mm}$ lateral from midline, and $2.0 \mathrm{~mm}$ ventral; Taubenfeld et al., 2001a). The rats were returned to their home cages and allowed to recover from surgery for $7 \mathrm{~d}$. At the indicated time points before or after training or retrieval, rats received bilateral injections of compounds as specified. All injections are indicated by arrows in the experimental schedule. All hippocampal injections were performed in $1 \mu \mathrm{l}$ per side. Hippocampal injections used a 28 gauge needle that extended $1.5 \mathrm{~mm}$ beyond the tip of the guide cannula and connected via polyethylene tubing to a Hamilton syringe. The infusions were delivered at a rate of $0.33 \mu \mathrm{l} / \mathrm{min}$ using an infusion pump. The injection needle was left in place for $2 \mathrm{~min}$ after the injection to allow complete dispersion of the solution. To verify proper placement of cannula implants, at the end of the behavioral experiments, rats were killed and their brains were postfixed with $10 \%$ buffered formalin. Forty micrometer coronal sections were cut through the hippocampus and examined under a light microscope. Rats with incorrect cannula placement $(<2 \%)$ were discarded from the study.

IA. IA was performed as previously described (Taubenfeld et al., 2001a). The IA chamber (Med Associates) consisted of a rectangular Perspex box divided into a safe compartment and a shock compartment. The safe compartment was white and illuminated and the shock compartment was black and dark. Footshocks were delivered to the grid floor of the shock chamber via a constant current scrambler circuit. The apparatus was located in a sound-attenuated, nonilluminated room. During training sessions, each rat was placed in the safe compartment with its head facing away from the door. After $10 \mathrm{~s}$, the door separating the compartments was automatically opened, allowing the rat access to the shock compartment; the rats usually enter the shock (dark) compartment within 10-20 s of the door opening. The door closed $1 \mathrm{~s}$ after the rat entered the shock compartment, and a $2 \mathrm{~s}$ footshock was administered. All initial behavioral experiments involving anti-BDNF, TrkB-Fc, anisomycin, and rapamycin were performed using a $0.6 \mathrm{~mA}$ footshock. Subsequent biochemistry and the behavioral experiments were performed using a $0.9 \mathrm{~mA}$ footshock, because higher shock intensity produces stronger molecular changes. To ensure that the behavioral results were confirmed with the higher footshock, we repeated both pretraining TrkB-Fc and post-training anti-BDNF injections using a $0.9 \mathrm{~mA}$ footshock and obtained comparable results (Fig. 5; Chen et al., 2012). Latency to enter the shock compartment was taken in seconds as acquisition. The rat was then returned to its home cage and tested for memory retention at the designated time point(s). Retention tests were done by placing the rat back in the safe compartment and measuring its latency to enter the shock compartment. Footshocks were not administered on the retention tests, and testing was terminated at $540 \mathrm{~s}$ or $900 \mathrm{~s}$, as detailed. In some experiments, as indicated, we also used, as a control, an unpaired IA paradigm. In this paradigm, rats were exposed to the context and $1 \mathrm{~h}$ later they were placed on the footshock grid and a footshock was immediately delivered. Hence, this protocol temporally dissociates, within subject, context and footshock exposure; this unpaired protocol does not produce IA memory retention (Chen et al., 2011). All behavioral tests were done blind to the experimental groups. For biochemical studies, rats were not tested for memory retention.

Drug and oligodeoxynucleotide injections. The sheep anti-BDNF antibody was purchased from Millipore and dissolved in $1 \times$ PBS. AntiBDNF antibody was injected at $0.5 \mu \mathrm{g}$ per injection per side. Recombinant human TrkB-Fc chimera was purchased from R\&D Systems and was dissolved in PBS. TrkB-Fc was injected at $0.5 \mu \mathrm{g}$ per injection per side. At these dosages, anti-BDNF and TrkB-Fc have been used to disrupt long-term memory consolidation when injected into the hippocampus (Alonso et al., 2002). Control sheep IgG was purchased from Sigma-Aldrich and dissolved in $1 \times$ PBS and injected at $0.5 \mu \mathrm{g}$ per injection per side. Recombinant BDNF and NT-3 were purchased from PeproTech and dissolved in PBS and injected at $0.25 \mu \mathrm{g}$ per injection per side. Recombinant IGF-II was purchased from R\&D Systems and dissolved in $0.1 \%$ BSA in $1 \times$ PBS. Anisomycin (Sigma-Aldrich) was dissolved in $0.9 \%$ saline, $\mathrm{pH} 7.4$, and injected at $125 \mu \mathrm{g} / \mu \mathrm{l}$. This dose blocks $>80 \%$ of protein synthesis in the dorsal hippocampus for up to $6 \mathrm{~h}$ (Milekic et al., 2006). Rapamycin was purchased from LC Laboratories, dissolved in DMSO, and diluted in $1 \times$ PBS to a final concentration of 1 $\mathrm{ng} / \mu \mathrm{l}$ per side. The dose of rapamycin used was previously shown to block S6 kinase phosphorylation and spatial memory in rats (Dash et al., 2006). Antisense oligodeoxynucleotides (ODNs) and relative scrambled sequences (SCR-ODNs) were injected at $2 \mathrm{nmol} / \mu \mathrm{l}$ in all antisense experiments. Sequences were as follows: C/EBP $\beta$ antisense ( $\beta$-ODN: $5^{\prime}$ CCAGCAGGCGGTGCATGAAC- $3^{\prime}$ ), C/EBP $\beta$ scrambled (SCR-ODN: 5'-TCGGAGACTAAGCGCGGCAC-3'), bdnf exon IV antisense (5'CAGTCACTACTTGTCAAAGTA- $\left.3^{\prime}\right)$, and $b d n f$ exon $I V$ scrambled ( $5^{\prime}$ ATTAACTACAAGCGTTCGACT-3'). The respective SCR-ODNs, which served as controls, contained the same base composition but in a random order and show no homology to sequences in the GenBank database. All ODNs were phosphorothioated on the three terminal bases of both 5' and 3' ends to produce increased stability. ODNs were reversephased-cartridge-purified and obtained from Gene Link.

Tissue preparation and Western blot analysis. Dorsal hippocampi were dissected in ice-cold cortical dissection buffer and snap frozen on dry ice. The tissues were homogenized using a Polytron homogenizer in lysis buffer $(0.2 \mathrm{~m} \mathrm{NaCl}, 5 \mathrm{~mm}$ EDTA, 10\% glycerol, 100 mm HEPES, $2 \mathrm{~mm}$ sodium phosphate) containing a protease inhibitor cocktail (Sigma; used as recommended by the manufacturer), $0.5 \mathrm{~mm}$ phenylmethylsulfonyl fluoride, $2 \mathrm{~mm}$ dithiothreitol, the phosphatase inhibitor cocktail (Sigma; used as recommended by the manufacturer), $2 \mathrm{~mm} \mathrm{NaF}, 1 \mu \mathrm{M}$ microcystin LR, and $1 \mathrm{~mm}$ sodium orthovanadate. Protein concentration was determined by using the Bio-Rad protein assay (Bio-Rad Laboratories). Five to $20 \mu \mathrm{g}$ of protein was resolved on $7.5 \%, 10 \%$, or $15 \%$ polyacrylamide gels, according to each marker's molecular weight, and then transferred to Immobilon-P membranes (Millipore). Membranes were blocked and incubated with primary antibodies according to manufacturers' recommendation. After the primary antibody incubation overnight at $4^{\circ} \mathrm{C}$, the membranes were washed and treated with a secondary horseradish peroxidase (HRP)-labeled goat anti-rabbit (1:4000) or goatanti-mouse (1:4000), as required, for $1 \mathrm{~h}$ at room temperature. Actin was used to account for loading variation. Membranes were washed and incubated with enhanced chemiluminescence detection reagents (GE Healthcare) and exposed to HyBlot CL Autoradiography Film (Denville Scientific). Quantitative densitometric analysis was performed using NIH Image software. Antibodies are as follows: anti-pCREB (1/1000) and anti-CaMKII $\alpha$ (1/2000; Millipore); anti-CREB (1/1000), anticofilin, and anti-pCaMKII $\alpha$ (1/5000; Cell Signaling Technology); antipCofilin (1:1000; Abcam); anti-C/EBP $\beta$ C-19 (1/1000); anti-BDNF (1: 1000); and anti-actin-HRP (1/4000; Santa Cruz Biotechnology).

Chromatin immunoprecipitation. Chromatin immunoprecipitation (ChIP) was performed as described previously (Tsankova et al., 2004). Rat hippocampi were dissected and minced into $\sim 1 \mathrm{~mm}$ pieces, and immediately cross-linked in 1\% formaldehyde for $17 \mathrm{~min}$ at room temperature with rotation. The cross-linking reaction was stopped by adding 
glycine to a final concentration of $0.125 \mathrm{M}$ and incubated for $7 \mathrm{~min}$. The tissue was washed five times in cold PBS containing protease inhibitor (Roche Applied Sciences) and then frozen on dry ice. The chromatin was solubilized and extracted by adding $500 \mu$ l of lysis buffer (1\% SDS, $50 \mathrm{~mm}$ Tris- $\mathrm{HCl}, \mathrm{pH} 8.1$, and $10 \mathrm{~mm}$ EDTA) followed by sonication. The homogenate was diluted in $1.1 \mathrm{ml}$ ChIP dilution buffer (1.1\% Triton X-100, $167 \mathrm{~mm} \mathrm{NaCl}, 16.7 \mathrm{~mm}$ Tris- $\mathrm{HCl}, \mathrm{pH}$ 8.1, $1.2 \mathrm{~mm}$ EDTA, and 0.01\% SDS). The homogenate was then used for ChIP. Thirty microliters of Magnetic Protein A beads (EZ-Magna ChIP A kit; Millipore) and $7.5 \mu \mathrm{g}$ of C/EBP $\beta$ antibody (Abcam), MeCP2 antibody (Abcam), Sin3a antibody (Abcam), HDAC2 antibody (Abcam), or pCREB antibody (Millipore) were added to the homogenate. The mixture was incubated rotating overnight at $4^{\circ} \mathrm{C}$. The wash, elution, and reverse cross-link to free DNA were all performed according to the manufacturer's protocol (EZ-Magna ChIP A/G kit). Specific primers were designed to amplify the proximal promoter region of $\sim 200 \mathrm{bp} 5^{\prime}$ of exon $I V$ of rat $b d n f$, which contains a putative $\mathrm{C} / \mathrm{EBP}$ binding site. Putative $\mathrm{C} / \mathrm{EBP}$ binding site was predicted using on-line programs AliBaba 2.1 and Matinspector. Similar C/EBP binding sites have been identified in other species (van Dijk et al., 1992). Primer sequences used were as follows: forward 5'GGC TTC TGT GTG CGT GAG TTC GC 3'; reverse 5'AAA GTG GGT GGG AGT CCA CGA G 3' based on previously published results (Martinowich et al., 2003). A standard 35 cycle PCR was performed as follows: denature at $95^{\circ} \mathrm{C}$ for $30 \mathrm{~s}$, anneal at $58^{\circ} \mathrm{C}$ for $30 \mathrm{~s}$ and extend for $30 \mathrm{~s}$ at $72^{\circ} \mathrm{C}$. The PCR was resolved on a $2 \%$ agarose gel and sequenced. Sequencing confirmed the identity of the fragment. DNA sequencing was performed by W.M. Keck Facility at Yale University, New Haven, CT. For ChIP time course studies, quantitative Real-Time PCR analysis was performed as described below.

Real-time quantitative RT-PCR. Hippocampal total RNA was extracted with TRIzol (Invitrogen) and reverse transcribed using SuperScript II RNase H minus RT (Invitrogen) or Bio-Rad iScript first-strand synthesis kit (Bio-Rad). Real-time PCR was done with an ABI Prism 7900HT (Applied Biosystems) or Bio-Rad My-IQ single-color RT-PCR machine; $500 \mathrm{pg}$ of the first-strand cDNA was subjected to PCR amplification using a QuantiTect SYBR Green PCR kit (Qiagen) or Bio-Rad iQ SYBR Green Supermix (Bio-Rad). Forty cycles of PCR amplification were performed as follows: denature at $95^{\circ} \mathrm{C}$ for $30 \mathrm{~s}$, anneal at $55^{\circ} \mathrm{C}$ for $30 \mathrm{~s}$, and extend for $30 \mathrm{~s}$ at $72^{\circ} \mathrm{C}$. Three PCR assays with triplicates were performed for each cDNA sample. Bdnf exon IV (Forward, 5' CCCAGTCTCTGCCTAGATCAAATGG 3', Reverse, 5' ACTCGCACGCCTTCAGTGAGAA 3'), Gapdh (Forward, 5'GAACATCATCCCTGCATCCA 3', Reverse 5'CCAGTGAGCTTCCCGTTCA 3') was used as internal control. Data were analyzed with Sequence Detector System version 2.0 software (Applied Biosystems). The cycle threshold method (CT; see Applied Biosystems User Bulletin Number 2, P/N 4303859), ddCT, was chosen to determine the relative quantification of gene expression in trained and control rats.

Statistical analyses. One-way ANOVA followed by Newman-Keuls post hoc tests was performed when comparing groups where a pairwise post hoc analysis of each group was required (Figs. 4, 5C-E). One-way ANOVA followed by Dunnett's post hoc tests was used when each group was compared with a single control group (Naive; Figs. $5 A, B, 7$ ). Twoway ANOVAs followed by Bonferroni post hoc tests were used when two factors were compared (e.g., treatment and testing; Figs. 1-3, 5, 6). Student's $t$ test was used when two groups were compared (e.g., reminder shock).

\section{Results}

Temporal evolution of hippocampal de novo proteinsynthesis requirement during memory consolidation

To define the temporal requirement of the dorsal hippocampal de novo protein synthesis during long-term IA memory consolidation, we bilaterally injected $125 \mu \mathrm{g}$ of the translation inhibitor anisomycin into the dorsal hippocampi of rats at $15 \mathrm{~min}$ before, immediately after, or $24 \mathrm{~h}, 48 \mathrm{~h}$, or $7 \mathrm{~d}$ after training. This dose blocks $>80 \%$ of protein synthesis in the dorsal hippocampus for up to $6 \mathrm{~h}$ (Milekic et al., 2006). Memory retention was tested at $2 \mathrm{~d}$
(Test 1) and $7 \mathrm{~d}$ (Test 2) after the injection, or, in specific cases, only at the indicated time.

Compared with vehicle, anisomycin injected $15 \mathrm{~min}$ before training completely disrupted memory retention at Tests 1 and 2 without affecting short-term memory tested at $1 \mathrm{~h}$ after training (Fig. $1 A, B$ ). At both Tests 1 and 2 the retention of the anisomycin-injected rats was not significantly different from acquisition, indicating that memory was completely disrupted. A reminder footshock of intensity equal to that of training in a different context $24 \mathrm{~h}$ after Test 2 did not reinstate the memory tested $24 \mathrm{~h}$ later (Test 3 ), indicating that the memory loss was not due to temporary retention/retrieval inhibition. Such a footshock rescues IA extinction (Inda et al., 2011).

Anisomycin injected immediately after training, while still causing significant memory impairment compared with vehicle (Tests 1 and 2), produced a significantly higher retention relative to acquisition, indicating that a few minutes of de novo protein synthesis following training is sufficient to produce some memory retention that lasts for $2 \mathrm{~d}$. A reminder shock $1 \mathrm{~d}$ after Test 2 failed to rescue the memory at Test 3 (Fig. 1C).

Rats injected with anisomycin $24 \mathrm{~h}$ after training had retentions similar to those of vehicle-injected controls $2 \mathrm{~d}$ later (Test 1), but 5 d later (Test 2) significantly lost their memory compared with controls (Fig. 1D). This loss of memory was not complete, as the retention was significantly higher than acquisition. To test whether Test 1 contributed to the effect seen at Test 2 (Inda et al., 2011), rats were given the same treatments and were tested only at $7 \mathrm{~d}$ after training (Fig. 1E). Compared with vehicle, anisomycin significantly impaired memory retention, indicating that translation at $24 \mathrm{~h}$ after training is required for memory persistence.

In contrast, anisomycin injected either at $2 \mathrm{~d}$ or $7 \mathrm{~d}$ after training had no effect on memory retention tested at $2 \mathrm{~d}, 7 \mathrm{~d}$, or $21 \mathrm{~d}$ after injection (Fig. $1 F, G$ ), indicating that the hippocampal de novo protein synthesis requirement for IA memory consolidation is completed by $2 \mathrm{~d}$ after training.

Finally, rapamycin, which is known to inhibit the mTOR pathway and target the translation of a subset of proteins in dendrites (Richter and Klann, 2009), injected 15 min before training completely disrupted memory retention, whereas the same treatment after training had no effect, indicating that a very brief phase of hippocampal, rapamycin-dependent mechanisms are required for IA memory consolidation (Fig. 2).

Thus, a rapid phase of de novo protein synthesis is required to initiate memory consolidation. This requirement persists for $>24 \mathrm{~h}$ and terminates by $48 \mathrm{~h}$ after training. Interfering with translation hours or a day after training leads to the formation of a memory, which, however, only persists for a few days, but then rapidly decays.

\section{The temporal evolution of $\mathrm{BDNF}$ requirement in the hippocampus during memory consolidation parallels that of de novo protein synthesis}

Based on previous studies showing that (1) BDNF leads to mTOR activation and protein synthesis, which are required for LTP and long-term memory formation (Tang et al., 2002; Slipczuk et al., 2009); (2) hippocampal blockade of BDNF or TrkB 15 min before training disrupts memory at $2 \mathrm{~d}$ after training without affecting short-term memory (Chen et al., 2012); (3) hippocampal BDNF is required at $12 \mathrm{~h}$ post training for the persistence but not formation of step-down IA memory (Bekinschtein et al., 2007a); and (4) BDNF rescues the memory decay caused by protein synthesis inhibitors injected $12 \mathrm{~h}$ after training in a step-down IA (Bekinschtein et al., 2008), we set out to determine whether 
A
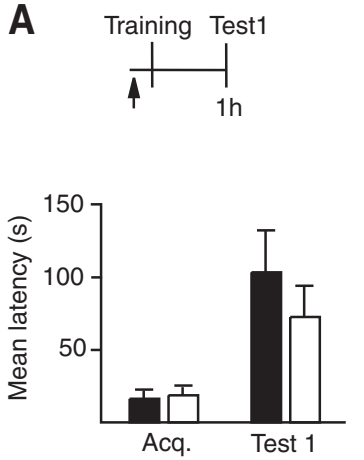

C

Training Test1 Test2 Reminder Test3
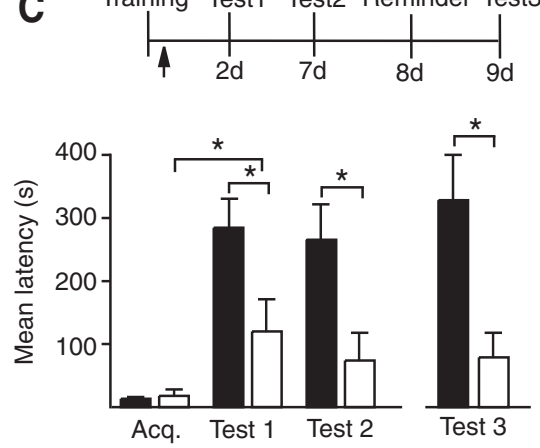

E
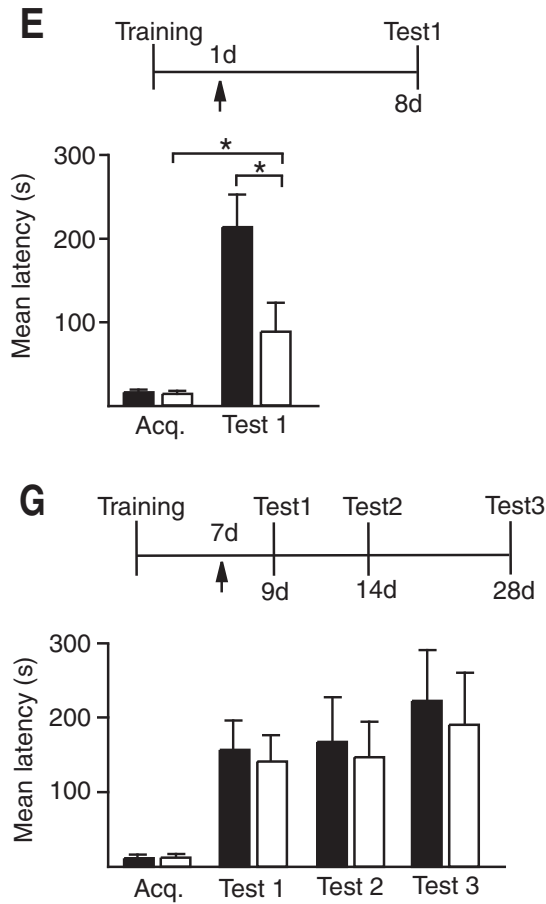

Figure 1. Temporal profile of the hippocampal protein synthesis requirement during memory consolidation. Experimental schedule is shown above each figure. $\boldsymbol{A}-\mathbf{G}$, Acquisition (Acq.) and retention are expressed as mean latency \pm SEM (in seconds) of rats given bilateral hippocampal injections (arrow) of vehicle or anisomycin at designated time points. $\boldsymbol{A}$, Hippocampal injections of anisomycin $15 \mathrm{~min}$ before IA training had no effect on short-term memory tested at $1 \mathrm{~h}$ after training ( $n=8 /$ group, Test 1 , vehicle vs anisomycin, $p>0.05$, Student's $t$ test). $\boldsymbol{B}$, Hippocampal injections of anisomycin 15 min before IA training disrupted memory tested 2 and $7 \mathrm{~d}$ after training ( $n=8-9$ /group, Test 1 and Test 2 , vehicle vs anisomycin, $p<0.01$, two-way ANOVA followed by Bonferroni post hoc tests; treatment effect $F_{(1,28)}=22.37, p<0.0001$ ) as well as $1 \mathrm{~d}$ after a reminder footshock (Test 3 , vehicle vs anisomycin, $p<0.01$, Student's $t$ test). Memory retention at Test 1, Test 2, or Test 3 was not significantly different from acquisition latency ( $p>0.05$, Student's $t$ test). C, Hippocampal injections of anisomycin immediately after IA training disrupted memory tested 2 and $7 \mathrm{~d}$ after training ( $n=8$ /group, Test 1 and Test 2 , vehicle vs anisomycin, $p<0.05$, tw0-way ANOVA followed by Bonferroni post hoc tests; treatment effect $\left.F_{(1,28)}=13.79, p=0.0009\right)$ as well as $1 \mathrm{~d}$ after a reminder footshock (Test 3 , vehicle vs anisomycin, $p<0.05$, Student's $t$ test). Memory retention at Test 1 was significantly different from
BDNF is both a fast upstream mediator of the rapid phase of translation required at training to initiate consolidation and a critical persistent mediator of the progression of the entire consolidation process. Hence, we tested whether the temporal progression of BDNF requirement parallels that of the entire protein synthesisdependent phase.

Pretraining bilateral injections into the dorsal hippocampus of either anti-BDNF or its receptor scavenger TrkB-Fc completely disrupted memory retention at both $2 \mathrm{~d}$ (Test 1; Fig. 3A) and $7 \mathrm{~d}$ after training compared with control IgG (Test 2). No reinstatement was found following a reminder footshock (Test 3; Fig. 3A).

The same treatments given immediately post training caused a nonsignificant trend toward memory decrease at Test 1 (Fig. $3 B$ ). This memory retention significantly decayed by Test 2 . No memory reinstatement was found following the reminder footshock (Test 3), indicating that the memory decline from Test 1 to Test 2 was not a result of extinction, but of consolidation impairment (Fig. 3B).

Further, similar to what was found with anisomycin, injection of TrkB-Fc $1 \mathrm{~d}$ after training did not affect retention $2 \mathrm{~d}$ later (Test 1; Fig. 3D) but significantly impaired memory tested only at $7 \mathrm{~d}$ after the injection (Fig. $3 C$, test 1, 8 d). Again similar to that of de novo protein synthesis, the requirement for BDNF signaling in the hippocampus was completed by $2 \mathrm{~d}$

\section{$\leftarrow$}

acquisition latency ( $p<0.05$, Student's $t$ test). $\boldsymbol{D}$, Hippocampal injections of anisomycin $1 \mathrm{~d}$ after IA training had no effect on memory tested $2 \mathrm{~d}$ after the injection ( $n=10 /$ group, Test 1 , vehicle vs anisomycin, $p>0.05$, two-way ANOVA followed by Bonferroni post hoc tests), but significantly disrupted memory retested at $7 \mathrm{~d}$ after the injection (Test $2, p<0.05$, twoway ANOVA followed by Bonferroni post hoc tests; treatment effect $\left.F_{(1,36)}=5.277, p=0.0275\right)$. Student's t test comparing Test 2 of the anisomycin group with its relative acquisition latency shows a statistically significant difference (Student's $t$ test, $p=0.0210$ ). $\boldsymbol{E}$, Hippocampal injections of anisomycin $1 \mathrm{~d}$ after IA training significantly disrupted memory tested at $7 \mathrm{~d}$ after the injection ( $n=8 /$ group, Test 1, vehicle vs anisomycin, $p<0.05$, Student's t test). Student's $t$ test comparing Test 1 of the anisomycin group with its relative acquisition latency shows a statistically significant difference (Student's $t$ test, $p=0.0412)$. $\boldsymbol{F}$, Hippocampal injections of anisomycin $2 \mathrm{~d}$ after training had no effect on memory tested $2 \mathrm{~d}$ (Test 1 ) or $7 \mathrm{~d}$ (Test 2) after the injection ( $n=12-14 /$ group, Test 1 and Test 2 , vehicle vs anisomycin, $p>0.05$, two-way ANOVA followed by Bonferroni post hoc tests for both experiments). $G$, Hippocampal injections of anisomycin $7 \mathrm{~d}$ after training had no effect on memory tested $2 \mathrm{~d}$ (Test 1), $7 \mathrm{~d}$ (Test 2), or $21 \mathrm{~d}$ (Test 3) after the injection ( $n=8-9 /$ group, Test 1 , Test2, and Test 3 , vehicle vs anisomycin, $p>0.05$, two-way ANOVA followed by Bonferroni post hoc tests); ${ }^{*} p<0.05,{ }^{* *} p<0.01$. 
A
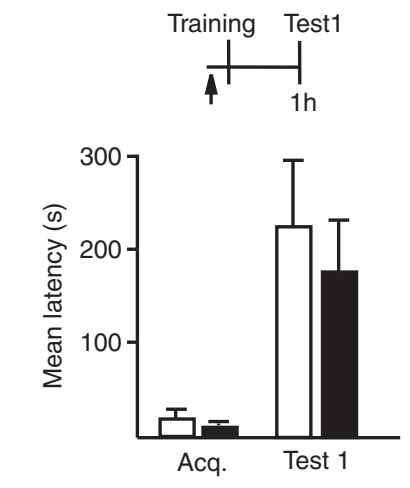

B
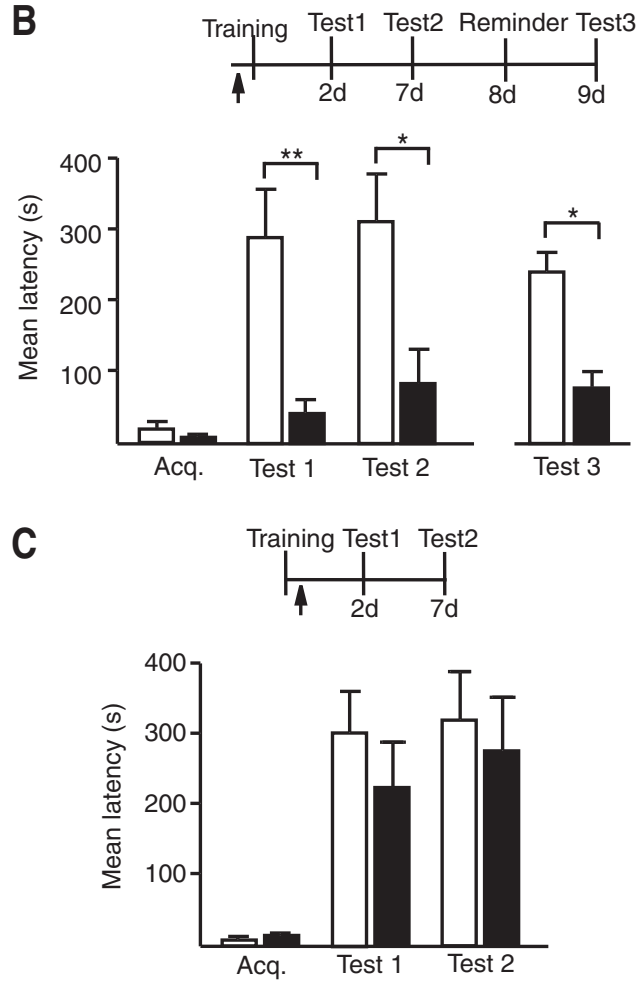

Vehicle

Rapamycin

Figure 2. A rapid rapamycin-sensitive phase is required for long-term memory consolidation. Experimental schedule above each figure (A-C). Acquisition (Acq.) and retention are expressed as mean latency \pm SEM (in seconds). Arrow indicates a bilateral hippocampal injection of vehicle or rapamycin $15 \mathrm{~min}$ before or immediately after IA training. Compared with vehicle, rapamycin injected 15 min before training $(\boldsymbol{A})$ did not affect short-term memory ( $n=7 /$ group, vehicle vs rapamycin, $p>0.05$, Student's $t$ test), but $(\boldsymbol{B})$ completely disrupted memory retention at both Test 1 and Test 2 ( $n=7 /$ group, Test 1 , vehicle vs rapamycin, $p<0.01$ rapamycin; Test 2 , vehicle vs rapamycin, $p<0.05$, two-way ANOVA followed by Bonferroni post hoc tests; treatment effect $F_{(1,24)}=19.77, p=0.0002$, each rapamycin group compared with Acq., $p>$ 0.05 Student's $t$ test). Memory did not reinstate following the reminder shock (Test 3 , vehicle vs rapamycin, $p<0.05$, Student's $t$ test). $C$, Rapamycin injected immediately after training had no effect on memory retention ( $n=9-10 /$ group, Test 1 and Test 2 , vehicle vs rapamycin, $p>$ 0.05 , two-way ANOVA followed by Bonferroni post hoc tests); ${ }^{*} p<0.05,{ }^{* *} p<0.01$.

after training. In fact, injecting anti-BDNF or TrkB-Fc either $2 \mathrm{~d}$ or $7 \mathrm{~d}$ after training had no effect on retention when tested 2,7 , and $21 \mathrm{~d}$ after the injection (Tests $1-3$; Fig. $3 D, E$ ).

Together, these data indicate that both BDNF signaling and de novo protein synthesis in the hippocampus follow a similar temporal progression of requirement during memory consolidation.
They also indicate that a rapid BDNF-dependent activation is critical for initiating memory consolidation and that a sustained or cycling activation of the BDNF-dependent pathway during the first $1-2 \mathrm{~d}$ after training is required for the completion of hippocampal memory consolidation.

Initial activation of BDNF signaling is required for initiating and maintaining a sustained increase in $\mathrm{PCREB}, \mathrm{C} / \mathrm{EBP} \beta$, pCaMKII $\alpha$, and pCofilin

Because consolidation requires gene expression, we then hypothesized that an autoregulatory-positive feedback loop of BDNFdependent increase in BDNF expression is a critical mechanism for memory consolidation.

We first examined the effect of blocking BDNF on posttraining temporal profiles of gene expression known to underlie IA memory formation. Previous results from Chen et al. (2012) showed that blocking BDNF in the dorsal hippocampus before training completely blocks the rapid (at $30 \mathrm{~min}$ ) IA trainingdependent induction of pCREB. This blockade persists at $20 \mathrm{~h}$ after training together with the blockade of phosphorylation of calcium pCaMKII $\alpha$ and Synapsin 1 .

Here we extended the investigation of molecular changes by testing the effect of pretraining anti-BDNF on the expression levels of the same and additional markers at $12 \mathrm{~h}$ after training. We chose this time point because it reflects the progression phase of the gene expression initiated at training. It also reports the changes occurring midway between the immediate phase after training and the $24 \mathrm{~h}$ time point at which protein synthesis and BDNF are still required. Quantitative Western blot analysis revealed that pretraining anti-BDNF treatment significantly blocks the training-dependent increase in hippocampal pCREB, phosphorylation of the actin severing protein cofilin (at Ser-9; pCofilin), and pCaMKII $\alpha$ as well as the induction of C/EBP $\beta$ (Fig. 4A). These changes were not observed in the hippocampi of rats that underwent an unpaired context- shock protocol (UN), which is known to not induce an IA memory [Student's $t$ test for all comparisons: $12 \mathrm{~h}$, pCREB: naive $=100.0 \pm 9.380(n=5), \mathrm{UN}=$ $81.05 \pm 12.47(n=6), p=0.27 ; \mathrm{C} / \mathrm{EBP} \beta$ : naive $=100.0 \pm 11.96$ $(n=5), \mathrm{UN}=81.34 \pm 16.46(n=6), p=0.40 ;$ pCaMKII $\alpha$ : naive $=100.0 \pm 16.99(n=5), \mathrm{UN}=82.98 \pm 9.508(n=6), p=$ 0.38; pCofilin: naive $=100.0 \pm 17.96(n=5), \mathrm{UN}=109.9 \pm$ $13.41(n=6), p=0.66 ; 20 \mathrm{~h}, \mathrm{BDNF}:$ naive $=100.0 \pm 10.31(n=$ $5), \mathrm{UN}=93.37 \pm 7.577(n=5), p=0.62]$.

No significant changes were observed in levels of total CREB, total CaMKII $\alpha$, or total cofilin (data not shown).

A summary of the temporal progression of hippocampal molecular changes occurring in vivo downstream BDNF in response to IA learning is shown in Figure $4 B$. All the changes after training are shown compared with the levels of naive rats killed at matched time points. Furthermore, in the hippocampi of rats exposed to unpaired context-shock, shock alone, or context alone and killed at matched time points, the levels of pCREB, pCaMKII $\alpha$, and $\mathrm{BDNF}$ have been found to be similar to those of naive rats, indicating that the training-dependent changes correlate with the context-shock association (Taubenfeld et al., 2001b; Chen et al., 2012). Hence, training-elicited molecular changes are shown compared with naive conditions.

All together, these data indicate that BDNF is necessary for the activation of the pCREB-C/EBP $\beta$-dependent cascade of events, which are sustained for $>24 \mathrm{~h}$. The progression and completion of this cascade of events are necessary for memory consolidation. 
$\mathrm{BDNF}$ is regulated by $\mathrm{C} / \mathrm{EBP} \boldsymbol{\beta}$ in the hippocampus during memory consolidation via an autoregulatorypositive feedback loop

CREB is required for BDNF transcription (Tao et al., 1998) and BDNF is known to mediate CREB activation (Finkbeiner et al., 1997; Pizzorusso et al., 2000; Alonso et al., 2002). Similarly, as shown above, the training-dependent induction of $\mathrm{C} / \mathrm{EBP} \beta$ in the hippocampus is also downstream BDNF and in vitro data indicate that, in addition to CREs, there are putative $\mathrm{C} / \mathrm{EBP}$ binding sites on BDNF promoters (Shieh et al., 1998; Tao et al., 1998; Takeuchi et al., 2002). We therefore tested whether the sustained BDNF-dependent requirement for memory consolidation for over $24 \mathrm{~h}$ could be due to a positive autoregulatory feedback loop of BDNF via $\mathrm{C} / \mathrm{EBP} \beta$.

Hence, we first investigated the temporal profile of $b d n f$ exon $I V$ mRNA, as this exon has been reported to be regulated in synaptic plasticity and memory consolidation (Hong et al., 2008; Lubin et al., 2008). Dorsal hippocampal RNA of rats killed at $40 \mathrm{~min}$ and 6, 12, 20, and $48 \mathrm{~h}$ after IA training was probed with quantitative real-time PCR (qRT-PCR) for $b d n f$ exon $I V$ mRNA. Results showed that, compared with naive rats, trained rats had a significant increase in bdnf exon $I V$ mRNA level at 12 and $20 \mathrm{~h}$ after training but not at the other time points tested (Fig. 5A).

To determine whether bdnfexon IV expression is critical for learning, we used an antisense ODN against a sequence selective for the bdnf exon $I V$ to knock down this transcript. Rats received bilateral hippocampal injections of either bdnf exon IV antisense (AS) or SCR ODN $6 \mathrm{~h}$ after IA training. AS injection significantly decreased BDNF levels at $20 \mathrm{~h}$ after training [AS $=64.32 \pm 4.254(n=5)$, SCR $=$ $100.0 \pm 12.01(n=5), p=0.0221$, Student's $t$ test], validating the knock-down effect of the AS. Compared with SCR, AS significantly impaired memory retention at both 2 and $7 \mathrm{~d}$ after training (Fig. $5 B$ ). Furthermore, the memory of the ASinjected rats was not reinstated by a reminder footshock (Fig. 5B), indicating that $b d n f$ exon $I V$ expression is in fact required for IA memory consolidation.

We then asked whether $b d n f$ exon $I V$ is a transcriptional target of $\mathrm{C} / \mathrm{EBP} \beta$ in vivo. ChIP of dorsal hippocampal extracts with an anti-C/EBP $\beta$ or a control IgG antibody (Fig. $5 C$ ) followed by PCR using primers flanking putative $\mathrm{C} / \mathrm{EBP} \beta$ binding sites on the $b d n f$ exon $I V$ promoter (Figs. $5 C, 7 A$ ) showed significant binding of anti-C/EBP $\beta$ compared with control IgG antibody (Fig. 5C). Hence, we conducted ChIP qRT-
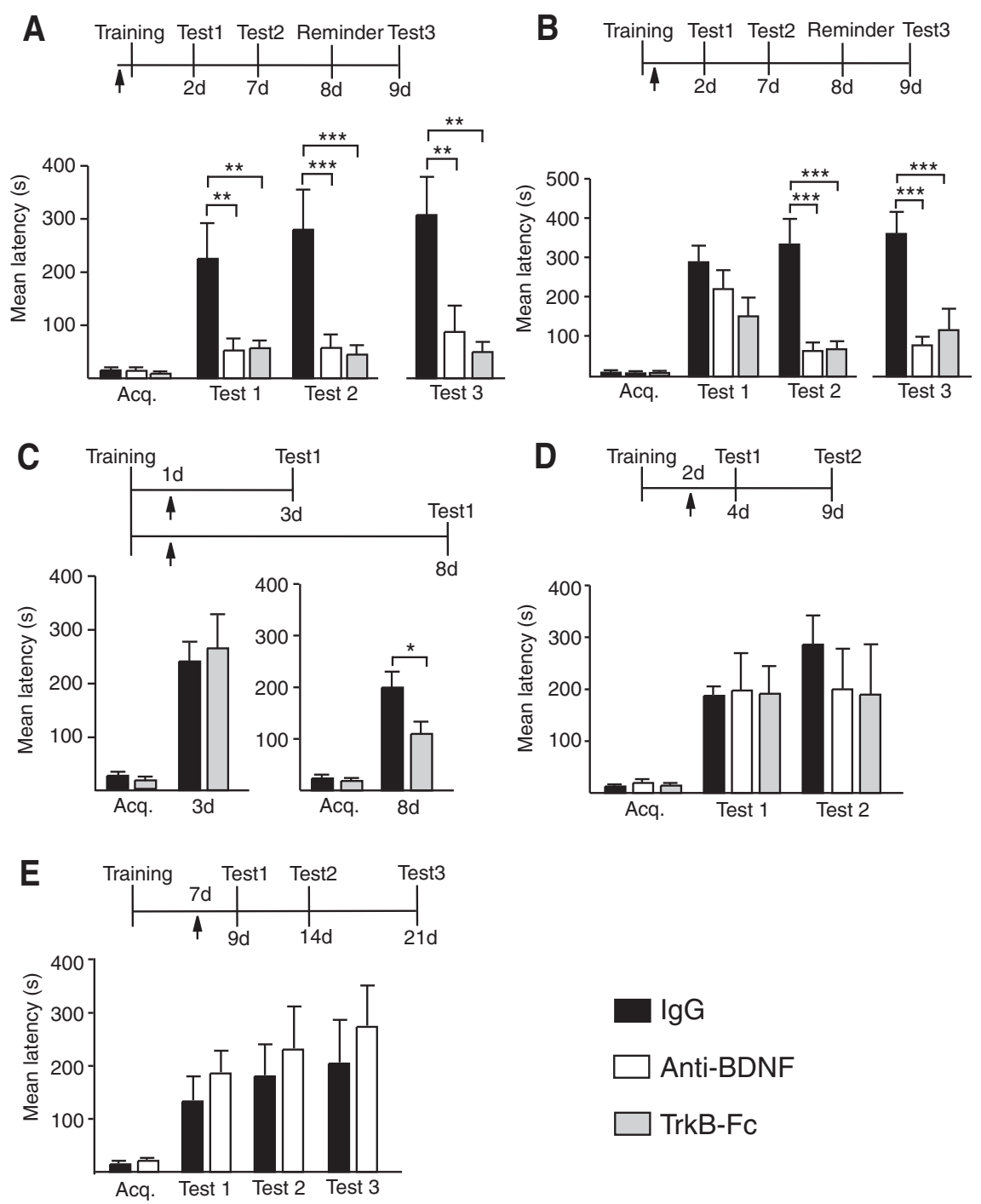

Figure 3. Temporal profile of hippocampal BDNF requirement during long-term memory consolidation. Experimental schedule above each figure. Acquisition (Acq.) and retention are expressed as mean latency \pm SEM (in seconds) of rats given a bilateral hippocampal injection (arrow) of IgG, anti-BDNF, or TrkB-Fc at designated time points $(\boldsymbol{A}-\boldsymbol{E})$. $\boldsymbol{A}$, Hippocampal injections of anti-BDNF or TrkB-Fc 15 min before IA training significantly disrupted memory tested at 2 and $7 \mathrm{~d}$ after training $(n=8-9 /$ group, IgG vs anti-BDNF or vs TrkB-Fc Test $1, p<0.01$ and Test $2, p<0.001$, two-way ANOVA followed by Bonferroni post hoc tests; treatment effect $F_{(2,46)}=17.08, p<0.0001$ ) as well as $1 \mathrm{~d}$ after a reminder footshock (Test 3, IgG vs anti-BDNF or vs TrkB-Fc, both treatments $p<0.01$, one-way ANOVA with Newman-Keuls multiple-comparison post hoc tests; treatment effect $F_{(2,25)}=8.174$, $p=0.0021)$. B , Hippocampal injections of anti-BDNF or TrkB-Fc immediately after training had no significant effect on memory tested $2 \mathrm{~d}$ after the injection ( $n=8-10$ /group, Test 1 , IgG vs anti-BDNF or vs TrkB-Fc $p>0.05$, two-way ANOVA followed by Bonferroni post hoc tests) but significantly disrupted memory retested $7 \mathrm{~d}$ after the injection (Test 2, both anti-BDNF and TrkB-Fc, $p<0.001$, two-way ANOVA followed by Bonferroni post hoc tests; treatment effect $\left.F_{(2,48)}=12.93, p<0.0001\right)$. The significant impairment persisted after a reminder shock (Test 3, both treatments $p<0.001$, one-way ANOVA followed by Newman-Keuls multiple-comparison post hoc tests; treatment effect $\left.F_{(2,26)}=9.958, p=0.0007\right)$. C, Hippocampal injections of TrkB-Fc $1 \mathrm{~d}$ after IA training had no effect on memory tested $2 \mathrm{~d}$ after the injection ( $n=8-9 /$ group, Test 1, $3 \mathrm{~d}$, IgG vs TrkB-Fc $p>0.05$, Student's $t$ test) but significantly disrupted memory tested $7 \mathrm{~d}$ after the injection ( $n=7-8$ /group, Test $1,8 \mathrm{~d}$, IgG vs TrkB-Fc $p<0.05$, Student's t test). $\boldsymbol{D}$, Hippocampal injections of anti-BDNF or TrkB-Fc $2 \mathrm{~d}$ after IA training had no effect on memory tested at $2 \mathrm{~d}$ (Test 1) or $7 \mathrm{~d}$ (Test 2) after the injection ( $n=6-9 /$ group, IgG vs anti-BDNF or vs TrkB-Fc $p>0.05$; two-way ANOVA followed by Bonferroni post hoc tests). $\boldsymbol{E}$, Hippocampal injections of anti-BDNF $7 \mathrm{~d}$ after IA training had no effect on memory tested at $2 \mathrm{~d}$ (Test 1), $7 \mathrm{~d}$ (Test 2), or $14 \mathrm{~d}$ (Test 3) after the injection ( $n=7 /$ group, IgG vs anti-BDNF $p>0.05$, two-way ANOVA followed by Bonferroni post hoc tests); ${ }^{*} p<0.05,{ }^{* *} p<0.01$, and ${ }^{* * *} p<0.001$.

PCR analysis on dorsal hippocampal extracts from rats trained and killed at $30 \mathrm{~min}$ or $12 \mathrm{~h}$ or $48 \mathrm{~h}$ after training. Compared with naive, the hippocampi of trained rats had a significant increase of $\mathrm{C} / \mathrm{EBP} \beta$ binding to the exon $I V$ promoter at $12 \mathrm{~h}$ but not at 30 min or $48 \mathrm{~h}$ after training when it returned to control levels (Fig. $5 C)$. This profile correlates with that of bdnf exon $I V$ mRNA as 
A
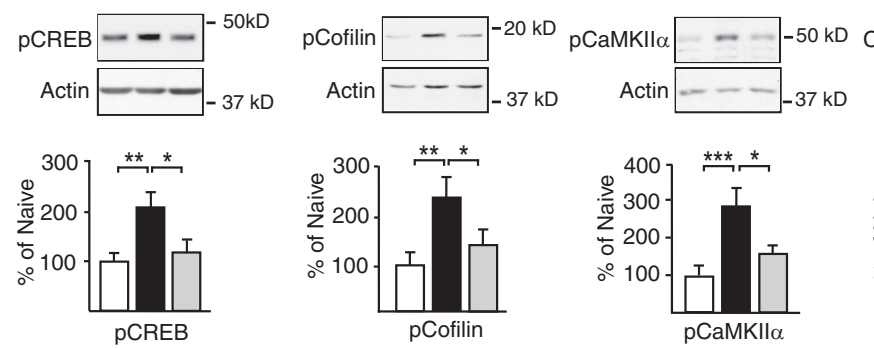

Naive-lgG

Trained-lgG

Trained-Anti-BDNF

B

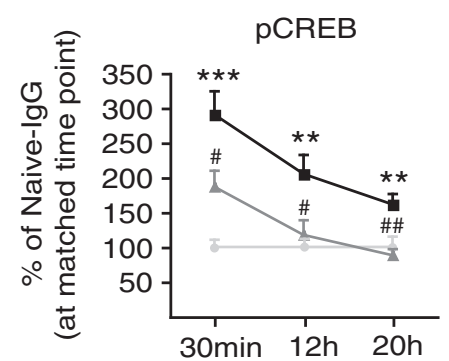

Time after training

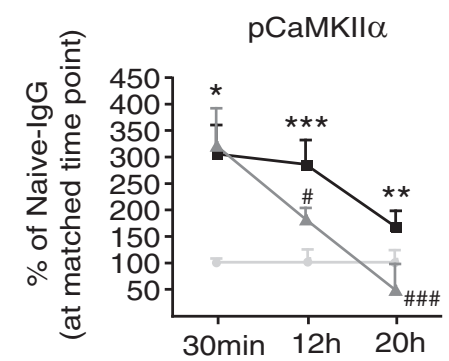

Time after training

\section{Naive-IgG}
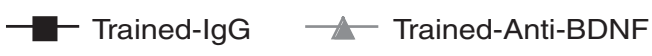

Figure 4. Hippocampal BDNF at training is required for the increase of pCREB, $\mathrm{pC}$ ofilin, $\mathrm{pCaMKIl} \alpha$, and C/EBP $\beta$. $A$, Examples and densitometric quantitative Western blot analyses of dorsal hippocampal extracts of naive and trained rats given hippocampal injections of $\mathrm{lg} \mathrm{G}$ or anti-BDNF 15 min before training and killed $12 \mathrm{~h}$ after training. The expression of $\mathrm{pCREB}, \mathrm{pCofilin}, \mathrm{pCaMKII} \alpha$, and C/EBP $\beta$ is significantly increased after training and this increase is significantly blocked by anti-BDNF injections ( $n=6-12$ / group, naive vs trained-IgG and naive vs trained-anti-BDNF, one-way ANOVA followed by Newman-Keuls multiple-comparison posthoc tests; pCREB: $F_{(2,30)}=7.608, p=0.0023 ; p$ Cofilin: $F_{(2,20)}=5.796, p=0.0114 ;$ pCaMKIl $\alpha: F_{(2,32)}=8.621, p=0.0011$; C/EBP $\left.\beta: F_{(2,23)}=5.308, p=0.0136\right)$. No significant changes were observed in levels of total CREB, total CaMKIIl $\alpha$, or total Cofilin ( $p>0.05$, data not shown). Data are expressed as mean percentage \pm SEM naive controls injected with lgG; ${ }^{*} p<0.05,{ }^{* *} p<$ 0.01 , and ${ }^{* * *} p<0.001$. $\boldsymbol{B}$, This figure summarizes the temporal profile of training-dependent increases in pCREB and pCaMKII $\alpha$ in dorsal hippocampal extracts obtained from rats injected with either anti-BDNF antibody or control lgG antibody 15 min before IA training ( $n=5-8 /$ group) and killed at $30 \mathrm{~min}$ or $12 \mathrm{~h}$ or $20 \mathrm{~h}$ after training. The graphs include previously reported data at 30 min and $20 \mathrm{~h}$ (Chen et al., 2012) in addition to the $12 \mathrm{~h}$ time point investigated here. Densitometric quantitative Western blot analyses data expressed as mean percentage \pm SEM naive, lgG-injected controls killed at matched time points. All values were normalized against actin. Compared with naive controls injected with IgG (light gray circles), rats trained in IA showed a significant induction of hippocampal pCREB and pCaMKII $\alpha$ at 30 min and 12 and $20 \mathrm{~h}$ after training (black squares). The induction of pCREB at all three time points and the induction of pCaMKII $\alpha$ at 12 and $20 \mathrm{~h}$ but not $30 \mathrm{~min}$ are blocked by an intrahippocampal injection of anti-BDNF 15 min before training (dark gray triangles; one-way ANOVA followed by Newman-Keuls multiple-comparison post hoc tests). ${ }^{*}$ Indicates significance levels comparing Naive-IgG to Trained-IgG groups, ${ }^{*} p<0.05,{ }^{* *} p<0.01$, and ${ }^{* * *} p<0.001$. \#Indicates significance levels comparing Trained-IgG to Trained-Anti-BDNF groups, $\# p<0.05$, \#\#p $<0.01$, and \#\#\# $<0.001$.

well as that of the training-induced C/EBP $\beta$ expression (Taubenfeld et al., 2001b), thus suggesting that $b d n f$ is likely a direct transcriptional target of $\mathrm{C} / \mathrm{EBP} \beta$ in the rat hippocampus in vivo.

To further define whether $b d n f$ is a functional target of $\mathrm{C} / \mathrm{EBP} \beta$, we determined whether blocking the training-induced upregulation of $\mathrm{C} / \mathrm{EBP} \beta$ affects the induction of $b d n f$ exon $I V$ mRNA. The antisense-mediated knockdown of $\mathrm{C} / \mathrm{EBP} \beta$ with the oligodeoxynucleotide $\beta$-ODN at $5 \mathrm{~h}$ after training, a protocol that has been shown to block the induction of C/EBP $\beta 12 \mathrm{~h}$ after training (Taubenfeld et al., 2001a), completely blocked the increase of bdnf exon IV mRNA measured by qRT-PCR analysis (Fig. 5D). Furthermore, the training-dependent induction of BDNF protein at $20 \mathrm{~h}$ after training was blocked by $\beta$-ODN in-
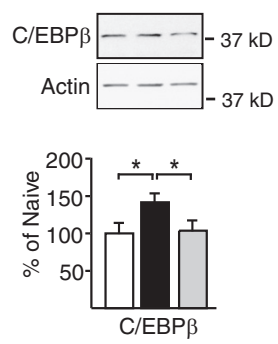

jected $5 \mathrm{~h}$ after training, confirming that the training-evoked $\mathrm{BDNF}$ increase is downstream C/EBP $\beta$ (Fig. $5 E$ ).

Since the induction of $\mathrm{C} / \mathrm{EBP} \beta$ requires BDNF at training (Fig. 4), we tested whether the bdnf exon IV mRNA induction at $12 \mathrm{~h}$ would also be blocked by pretraining injections of an anti-BDNF antibody. qRT-PCR analysis revealed that compared with IgG, anti-BDNF antibodies injected 15 min before training blocked the induction of bdnf exon $I V$ at $12 \mathrm{~h}$ after training (Fig. 5F).

Together, these data indicate that a rapid BDNF signaling at training leads to the recruitment of the CREB-C/EBP pathway, which in turn via $\mathrm{C} / \mathrm{EBP} \beta$ upregulates the expression of BDNF. This autoregulatory-positive feedback loop is required for the successful completion of memory consolidation.

\section{BDNF rescues the memory impairment mediated by C/EBP $\beta$ knockdown}

Given that BDNF recruits the CREB-C/ EBP pathway to regulate its own expression, we asked whether BDNF is sufficient to rescue the memory impairment caused by C/EBP $\beta$ knockdown 5 h after IA training. Rats received bilateral hippocampal injections of either $\beta$-ODN or SCR-ODN $5 \mathrm{~h}$ after IA training. The $\beta$-ODN-injected rats were further divided into three groups: one was coinjected with recombinant BDNF (Rec-BDNF), one with vehicle, and the third with another recombinant trophic factor, neurotrophin 3 (Rec-NT3). All rats were tested $2 \mathrm{~d}$ (Test 1) and $7 \mathrm{~d}$ (Test 2) after training. Confirming our previous result, compared with SCR-ODN, $\beta$-ODN significantly impaired memory retention at both 2 and $7 \mathrm{~d}$ after training (Fig. 6A). BDNF significantly and completely rescued this amnesia while NT3 did not. Moreover, the rescuing effect of BDNF persisted over time (Fig. 6A). Thus, BDNF selectively rescues the memory impairment mediated by $\mathrm{C} / \mathrm{EBP} \beta$ knockdown.

To investigate whether the rescuing effect of BDNF occurs during the temporally restricted window of the CREB-C/EBP-dependent gene expression phase, which, as shown above, regulates the endogenous increase in BDNF, we monitored the effect of rec-BDNF hippocampal injection over time. Rats received bilateral intrahippocampal injections of either $\beta$-ODN or SCR-ODN $5 \mathrm{~h}$ after IA training. Both groups received either vehicle or rec-BDNF at $12 \mathrm{~h}$, $2 \mathrm{~d}$, or $4 \mathrm{~d}$ after training and were tested at $2 \mathrm{~d}$ (Test 1 ) and $7 \mathrm{~d}$ (Test 2) after injection (Fig. 6B-D). Rec-BDNF selectively and completely rescued the memory impairment caused by $\beta$-ODN when injected at $12 \mathrm{~h}$ after training without changing memory retention when injected with SCR-ODN (Fig. $6 B$ ). This effect was selective, because IGF-II, another C/EBP $\beta$ target growth factor, did not rescue the memory deficit caused by C/EBP $\beta$ knock- 
A

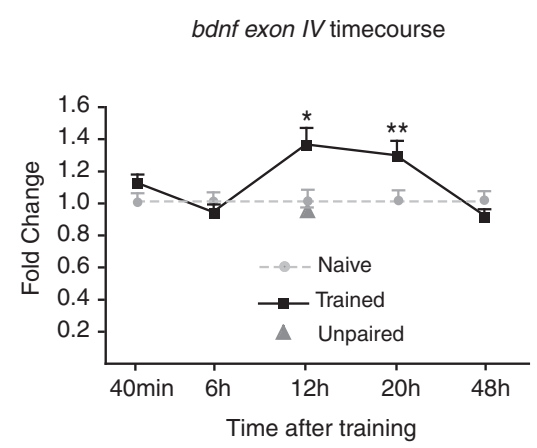

D
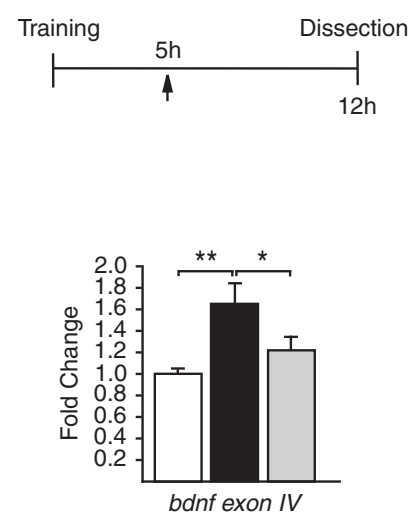

Naive- SCR-ODN
B
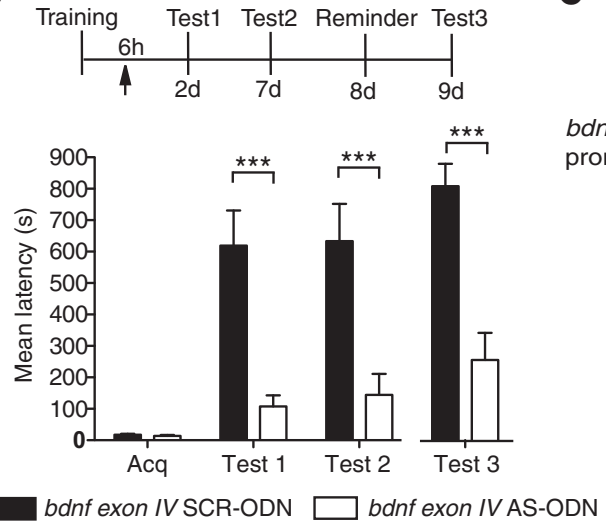

E

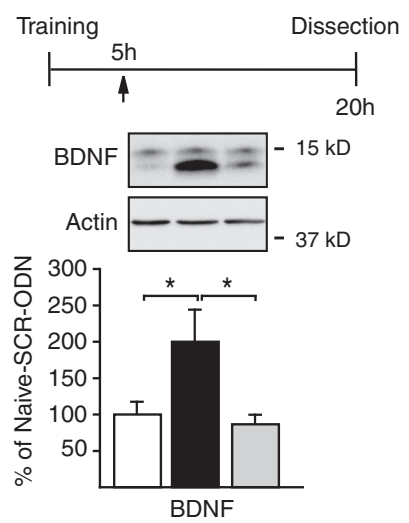

C
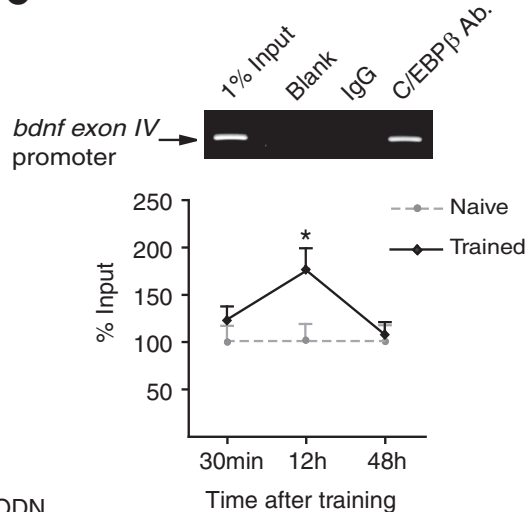

$\mathbf{F}$
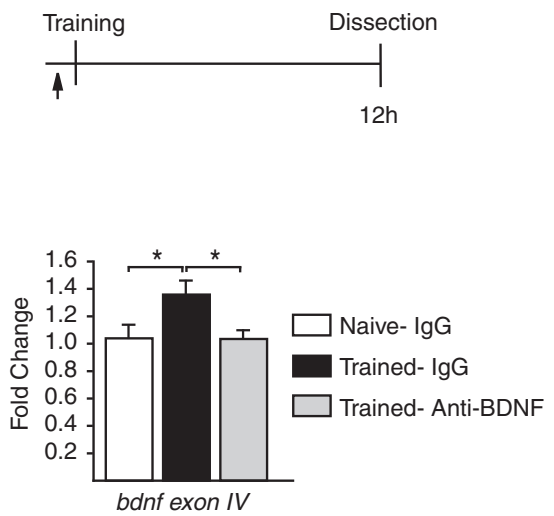

Figure 5. BDNF recruits C/EBP $\beta$ in an autoregulatory-positive feedback loop. $A, q R T-P C R$ analysis of $b d n f$ exon IV on dorsal hippocampal cDNAs of trained rats killed at the indicated time points (normalized to gapdh). Compared with naive, training significantly increased bdnf exon IV levels at 12 and $20 \mathrm{~h}$ post training ( $n=4-8 /$ group; $12 \mathrm{~h}, p<0.05 ; 20 \mathrm{~h}, p<0.01 ;$ one-way ANOVA followed by Dunnett's multiple-comparison post hoc test). No increase in bdnf exon IV levels occurred in the hippocampi of rats at $12 \mathrm{~h}$ after exposure to both context and shock separated by $1 \mathrm{~h}$ (unpaired protocol). Data are expressed as mean fold change \pm SEM. $B, B d n f$ exon IV AS, but not SCR ODN, disrupted memory consolidation. Experimental schedule shown above the graph. ODNs were injected (arrow) $6 \mathrm{~h}$ after IA training. Rats were tested $2 \mathrm{~d}$ (Test 1 ) and $7 \mathrm{~d}$ (Test 2) after training. Compared with SCR, AS significantly decreased memory retention at both Tests 1 and 2 ( $n=$ 9-10/group; AS vs $S C R, p<0.001$, two-way ANOVA followed by Bonferroni post hoc tests; treatment effect $\left.F_{(1,51)}=29.14\right)$. No significant reinstatement was observed following a reminder footshock $(p>0.05)$. Data are expressed as mean latency \pm SEM. ${ }^{* * *} p<0.001$. C, Representative PCR fragments in agarose gel stained with ethidium bromide and graphs showing $q R T-P C R s$ of bdnf exon IV promoter obtained following ChIP with an anti-C/EBP $\beta$. These fragments were obtained from dorsal hippocampi of trained rats killed at $30 \mathrm{~min}$ or $12 \mathrm{~h}$ or $48 \mathrm{~h}$ after training. Training resulted in a significant increase in C/EBP $\beta$ binding to the $b d n f$ exon IV promoter $12 \mathrm{~h}$ after training $(n=4 /$ group; naive vs trained, $12 \mathrm{~h}, p<0.05$, one-way ANOVA followed by Dunnett's multiple-comparison post hoc test; $\left.F_{(3,15)}=3.998, p=0.0346\right)$. Data are presented as mean percentage input enrichment \pm SEM. $D$, qRT-PCR analysis of $b d n f$ exon $/ V$ in hippocampi of naive and trained rats injected (arrow) with either SCR-ODN or $\beta$-ODN $5 \mathrm{~h}$ after training and killed $12 \mathrm{~h}$ after training (normalized to gapdh). Training significantly increased bdnf exon $/ V$ levels at $12 \mathrm{~h}$; this increase was blocked by $\beta-0 D N(n=6-8 /$ group; naive-SCR-ODN vs trained SCR-ODN $p<0.01$, trained-SCR-ODN vs trained $\beta-0 D N p<0.05$, one-way ANOVA followed by Newman-Keuls multiple-comparison post hoc tests; $\left.F_{(2,21)}=8.136, p=0.0028\right)$. Data are expressed as mean fold change \pm SEM. $E$, Western blot examples and densitometric quantitative Western blot analyses of BDNF protein levels in dorsal hippocampal extracts from naive and trained rats injected (arrow) with either SCR-ODN or $\beta-0 D N 5 \mathrm{~h}$ after training and killed $20 \mathrm{~h}$ after training (normalized to actin). Training significantly increased BDNF levels at $20 \mathrm{~h}$; this increase was blocked by $\beta-0 \mathrm{DN}(n=6-8 /$ group; naive-SCR-ODN vs trained SCR-ODN and trained-SCR-ODN vs trained $\beta-0 D N p<0.05$, one-way ANOVA followed by Newman-Keuls multiple-comparison post hoc tests; $\left.F_{(2,20)}=5.568, p=0.0131\right)$. Data are expressed as mean percentage \pm SEM naive controls injected with SCR-ODN.F, qRT-PCR analysis of $b d n f$ exon IV CDNA obtained from dorsal hippocampi of naive and trained rats injected (arrow) with either lgG or anti-BDNF 15 min before training and killed $12 \mathrm{~h}$ after training (normalized to gapdh). Anti-BDNF blocked the training-dependent significant increase in bdnfexon $/ V(n=8-12 /$ group; naive-lgG vs trained-lgG and trained-lg vs trained-anti-BDNF $p<$ 0.05 , one-way ANOVA followed by Newman-Keuls multiple-comparison post hoc tests; $\left.F_{(2,27)}=4.949, p=0.0155\right)$. Data are expressed as mean fold change \pm SEM; ${ }^{*} p<0.05,{ }^{* *} p<0.01$.

down. Notably, BDNF no longer rescued the memory impairment if injected at $2 \mathrm{~d}$ or $4 \mathrm{~d}$ after training (Fig. $6 C, D$ ), suggesting that the effect is limited to the gene expression-dependent consolidation phase. Thus, BDNF rescues the memory impairment caused by $\mathrm{C} / \mathrm{EBP} \beta$ knockdown in a selective and temporally restricted manner. The temporal window within which this effect occurs is similar to that of the requirement for hippocampal de novo protein synthesis critical for memory consolidation, lending further support for our hypothesis that BDNF mediates at least part of the protein synthesis required for memory consolidation.
Last, since pretraining anti-BDNF antibody led to amnesia and blocked the induction of C/EBP $\beta$ at $12 \mathrm{~h}$ after training, we tested whether rec-BDNF could rescue this amnesia. Rats were given intradorsal hippocampal injections of anti-BDNF or IgG 15 min before IA training; $12 \mathrm{~h}$ later, while the anti-BDNF rats were injected with either rec-BDNF or vehicle, the IgGinjected controls received vehicle. All rats were tested at $2 \mathrm{~d}$ (Test 1 ) and $7 \mathrm{~d}$ (Test 2) after training (Fig. 6E). BDNF failed to rescue the memory deficit caused by pretraining intrahippocampal anti-BDNF injections (Fig. $6 E$ ), suggesting that pre- 
A
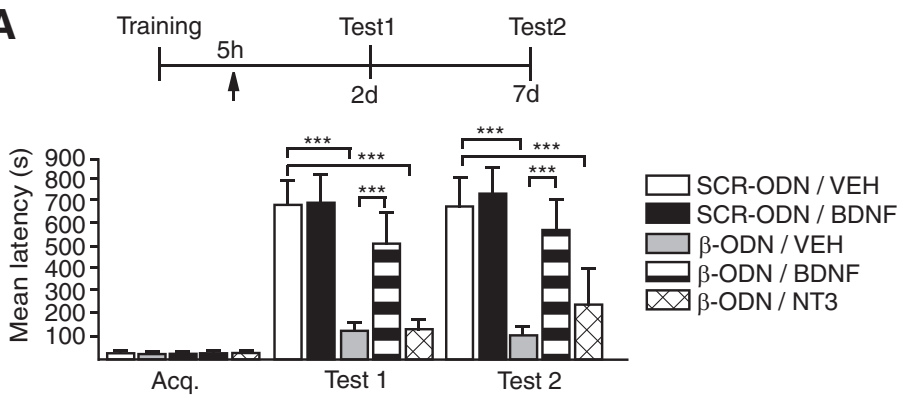

B
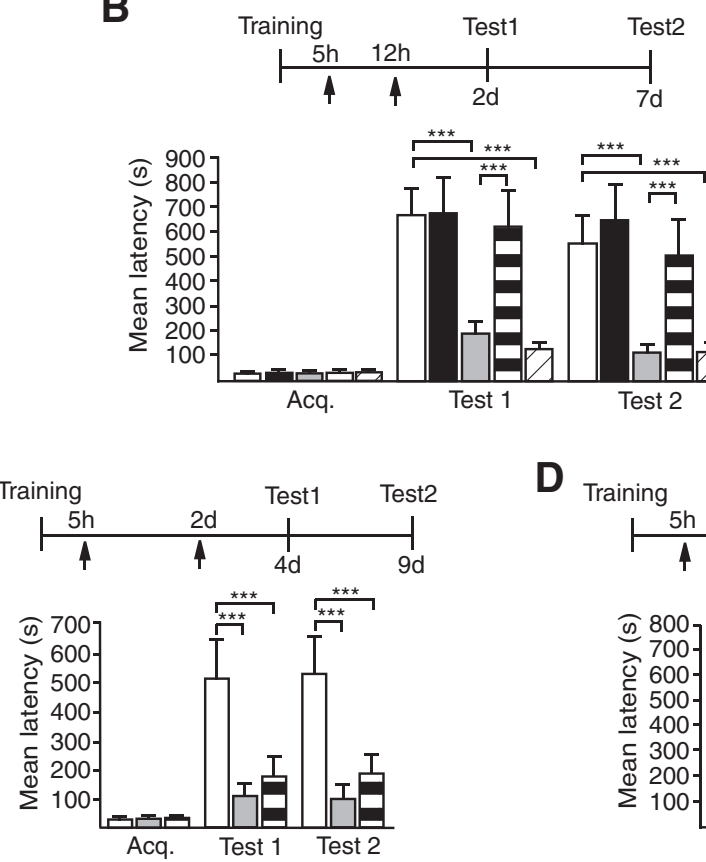

SCR-ODN / VEH

$\beta-O D N$ / VEH
D Training
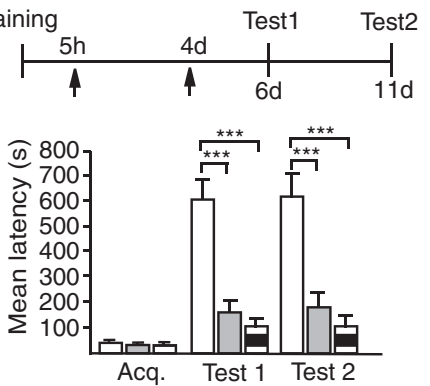

$\beta-O D N / B D N F$
$\mathbf{F}$
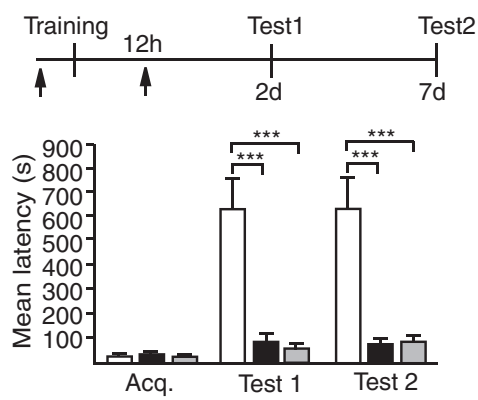

$\square$ IgG / VEH $\square$ Anti-BDNF / VEH $\square$ Anti-BDNF / BDNF

\section{E}

Figure 6. The memory impairment due to $C / E B P \beta$ or BDNF blockade after training is rescued by BDNF. Data are expressed as mean latency \pm SEM. Experimental schedule is shown above each figure $(\boldsymbol{A}-\boldsymbol{F})$. $\boldsymbol{A}$, Rec-BDNF but not rec-NT3 injected $5 \mathrm{~h}$ after IA training rescued the memory impairment caused by blocking C/EBP $\beta$ expression. $\beta$-ODN or SCR-ODN was injected (arrow) $5 \mathrm{~h}$ after IA training along with rec-BDNF, Rec-NT3, or Vehicle. Rats were tested $2 \mathrm{~d}$ (Test 1 ) or $7 \mathrm{~d}$ (Test2) after the injection. Compared with SCR-ODN, $\beta$-ODN significantly impaired memory retention at both 2 and $7 \mathrm{~d}$ after training $(n=6-8 / g$ roup; SCR-ODN/VEH vs $\beta$-0DN/VEH, $p<0.001$, two-way ANOVA followed by Bonferroni post hoc tests; treatment effect $F_{(4,58)}=13.73, p<0.0001$ ). BDNF, but not NT3, significantly and completely rescued this amnesia and the rescuing effect persisted ( $\beta-0 D N / V E H$ vs $\beta-0 D N /$ BDNF, $p<0.001 ; \beta$-0DN/VEH vs $\beta$-0DN/NT-3, $p>0.05$; SCR-0DN/VEH vs $\beta$-0DN/BDNF, $p>0.05$, two-way AN0VA followed by Bonferroni post hoc tests). $\boldsymbol{B}$, Rec-BDNF but not rec-IGF-II injected at $12 \mathrm{~h}$ after IA training significantly and completely rescued the memory impairment caused by $\beta$-0DN injected $5 \mathrm{~h}$ after training ( $n=6-11 /$ group, $\beta$-ODN/VEH vs $\beta-0 D N / B D N F, p<0.001$ $\beta$-ODN/VEH vs $\beta$-ODN/IGFII, $p>0.05$; SCR-0DN/VEH vs $\beta$-0DN/BDNF $p>0.05$, two-way ANOVA followed by Bonferroni post hoc tests; treatment effect $F_{(2,34)}=13.51, p<0.0001$ ). Rats were tested $2 \mathrm{~d}$ (Test 1$)$ or $7 \mathrm{~d}$ (Test 2) after the injection. $\boldsymbol{C}, \boldsymbol{D}$, Rec-BDNF training blockade of BDNF completely prevents the rapid changes that initiate the consolidation process on which BDNF can act to rescue the memory. In contrast, blocking $\mathrm{C} / \mathrm{EBP} \beta$ induction at $5 \mathrm{~h}$ post training using $\beta$-ODN allows for at least $5 \mathrm{~h}$ of consolidation mechanisms, which leaves substrate/s at $12 \mathrm{~h}$ on which BDNF rescues the memory. To exclude that the anti-BDNF antibody injected 15 min before training was still present at $12 \mathrm{~h}$ after training, thus preventing the rescuing effect of BDNF at $12 \mathrm{~h}$, anti-BDNF antibody was delivered into the dorsal hippocampi of rats immediately after training followed by injection of either vehicle or rec-BDNF $12 \mathrm{~h}$ after training. As shown in Figure $3 B$, we confirmed that the post-training injection of anti-BDNF failed to significantly change memory at $2 \mathrm{~d}$ after training but significantly disrupted it at $7 \mathrm{~d}$ after training. This decay was completely rescued by rec-BDNF injected at $12 \mathrm{~h}$ after training (Fig. $6 F$ ), confirming that a rapid, BDNF-dependent mechanism is required for the rescuing effect of BDNF at later times.

Hence, BDNF is sufficient to rescue the memory impairment caused by hippocampal C/EBP $\beta$ knockdown during a temporally restricted window that overlaps with that of the de novo proteinsynthesis requirement for consolidation. Moreover, BDNF can rescue a memory only if the consolidation process has been initiated or is ongoing, but not beyond this temporal window.

\section{$\leftarrow$}

injected $2 \mathrm{~d}(\boldsymbol{C})$ or $4 \mathrm{~d}(\boldsymbol{D})$ after training did not rescue the memory impairment caused by blocking C/EBP $\beta$ expression. $\beta-O D N$ or SCR-ODN was injected $5 \mathrm{~h}$ after IA training. Rats were tested $2 \mathrm{~d}$ (Test 1 ) or $7 \mathrm{~d}$ (Test 2) after the injection ( $n=$ $6-8 /$ group; $\beta$-ODN/VEH vs $\beta$-ODN/BDNF, $p>0.05$, twoway ANOVA followed by Bonferroni post hoc tests; treatment effect: for $C, F_{(2,34)}=13.51, p<0.0001$; for $D, F_{(2,40)}=$ $46.42, p<0.0001), E$, Rec-BDNF injected $12 \mathrm{~h}$ after IA training does not rescue the memory impairment caused by pretraining anti-BDNF. IgG or anti-BDNF antibody was injected (arrow) 15 min before training. Rec-BDNF or vehicle was injected (arrow) $12 \mathrm{~h}$ after training. Rats were tested $2 \mathrm{~d}$ (Test 1 ) or $7 \mathrm{~d}$ (Test 2) after the injection ( $n=6-7 /$ group; anti-BDNF/VEH vs anti-BDNF/BDNF, $p>0.05$, two-way ANOVA followed by Bonferroni post hoc tests; treatment effect $F_{(2,32)}=41.39$, $p<0.0001) . F$, Rec-BDNF injected $12 \mathrm{~h}$ after IA training rescues the memory decay caused by post-training anti-BDNF injection. IgG or anti-BDNF antibody was injected (arrow) immediately after training. Rec-BDNF or Vehicle was injected (arrow) $12 \mathrm{~h}$ after training. Rats were tested $2 \mathrm{~d}$ (Test 1 ) or $7 \mathrm{~d}$ (Test 2) after the injection ( $n=9-10 /$ group; anti-BDNF/VEH vs anti-BDNF/BDNF, Test $2, p<0.001$, two-way ANOVA followed by Bonferroni post hoc tests; treatment effect $F_{(2,50)}=$ $8.36, p=0.0007) ;{ }^{* * *} p<0.001$. 
BDNF-dependent transcriptional repression and the termination of the feedback loop correlate with binding of HDAC2, MeCP2, and Sin3A to its promoter

Which mechanism ends the temporal window of de novo protein synthesis and BDNF autoregulatory feedback loop by $48 \mathrm{~h}$ after training? Since $b d n f$ mRNA levels return to baseline by $48 \mathrm{~h}$ after training, we hypothesized that repressing chromatin structure at the bdnf exon $I V$ might act as a molecular brake that signals the end of the BDNF feedback loop. Moreover, the training-dependent increases in pCREB and C/EBP $\beta$ also return to control levels by $48 \mathrm{~h}$. We therefore examined the binding of pCREB and C/EBP $\beta$ as well as the transcriptional repressor $\mathrm{MeCP} 2$, along with its corepressors HDAC2 and Sin $3 \mathrm{a}$ at the bdnf exon IV promoter, because these factors have previously been implicated in transcriptional control of the bdnf exon IV promoter in vitro (Chen et al., 2003; Martinowich et al., 2003).

ChIPs with anti-pCREB, anti-C/EBP $\beta$, anti-MeCP2, anti-HDAC2, and anti-Sin3a of dorsal hippocampal extracts taken from trained rats killed $30 \mathrm{~min}, 12 \mathrm{~h}$, or $48 \mathrm{~h}$ after training followed by qRT-PCR analysis of the bdnf exon $I V$ promoter region (Fig. $7 A$ ) revealed that $\mathrm{pCREB}$ and $\mathrm{C} / \mathrm{EBP} \beta$ binding at the bdnf exon $I V$ promoter is significantly increased at $12 \mathrm{~h}$ but not 30 min after training and returns to naive control levels by $48 \mathrm{~h}$ (Figs. $7 B, C, 5 B$ ). Conversely, MeCP2 exhibited significantly higher binding to the $b d n f$ exon $I V$ promoter at $48 \mathrm{~h}$ but not at $30 \mathrm{~min}$ or $12 \mathrm{~h}$ after training compared with naive controls (Fig. 7 B,D). Similarly, HDAC2 binding was significantly increased at $48 \mathrm{~h}$ after training but not at earlier time points (Fig. 7E). We also observed significantly increased $\operatorname{Sin} 3$ a binding at $30 \mathrm{~min}$ and $48 \mathrm{~h}$ but not $12 \mathrm{~h}$ after training, indicating that $\operatorname{Sin} 3$ a may have different binding partners at different time points. Notably, Sin3a binding to the exon $I V$ promoter appears anti-correlated with bdnf exon $I V$ mRNA expression (Fig. $7 F$ ). These data imply that increased transcriptional repression at the bdnf exon $I V$ promoter, likely mediated by MeCP2, HDAC2, and Sin3a, with consequent decrease in BDNF transcription at $48 \mathrm{~h}$ after training, accompanies the termination of the consolidation process.

\section{Discussion}

We have shown that, to consolidate, IA memory requires hippocampal de novo protein synthesis that begins very rapidly at training, lingers for $>24 \mathrm{~h}$, and ends by $48 \mathrm{~h}$ after training. A key mechanism paralleling this process is BDNF release and its ex-
A

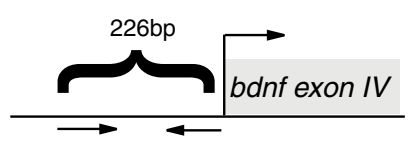

C

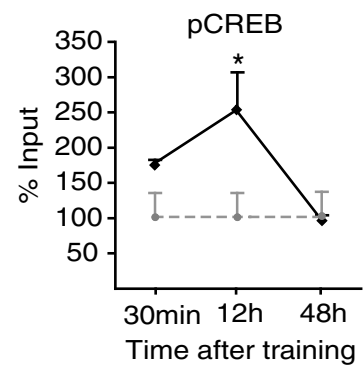

E

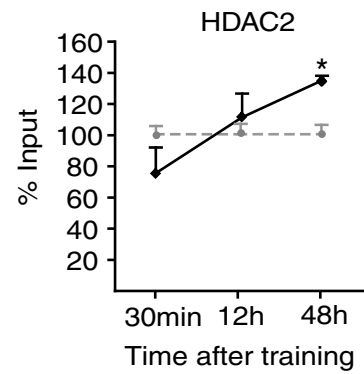

B

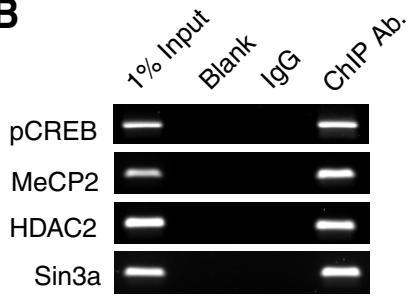

D

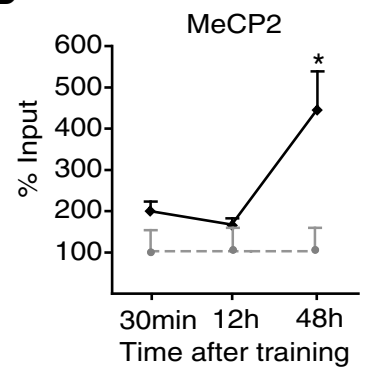

$\mathbf{F}$

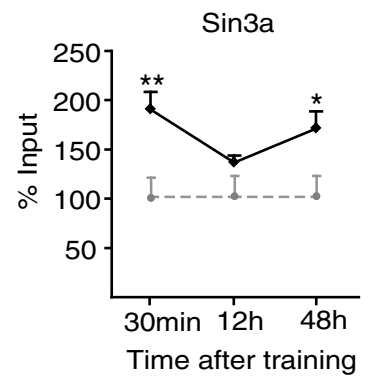

G

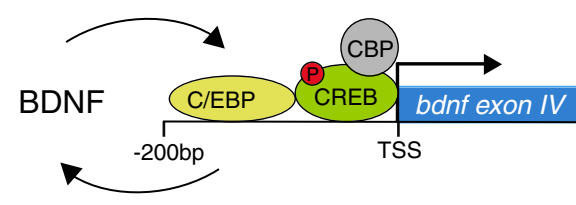

12 Hours after IA training

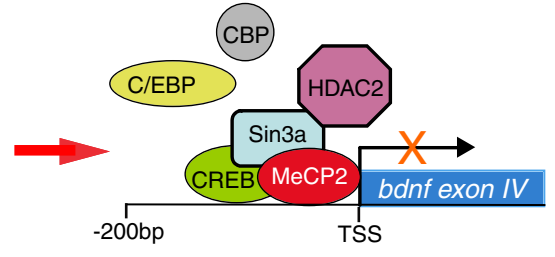

48 Hours after IA training

Figure 7. Increased ratio of repressor/activator binding at the bdnf exon IV promoter correlates with the termination of the feedback loop. $A$, Scheme of the $226 \mathrm{bp}$ upstream region of bdnf exon IV promoter analyzed with ChIP. B, Representative PCR fragments in agarose gel stained with ethidium bromide and $(\boldsymbol{C}-\boldsymbol{F}) \mathrm{qRT}$-PCR analysis of $b d n f$ exon $/ V$ promoter fragment following ChIP using an antibody against pCREB, MeCP2, HDAC2, or Sin3a. The qRT-PCRs were obtained from dorsal hippocampi of trained rats killed at $30 \mathrm{~min}$ or $12 \mathrm{~h}$ or $48 \mathrm{~h}$ after training. Data are presented as mean percentage input enrichment \pm SEM ( $n=$ $4-7 /$ group; $p<0.05, p<0.01$, one-way ANOVA followed by Dunnett's multiple-comparison post hoc test; $\mathrm{pCREB}: F_{(3,15)}=$ $\left.5.437, p=0.0136 ; \mathrm{MeCP} 2: F_{(3,15)}=7.069, p=0.0054 ; \operatorname{HDAC2}: F_{(3,19)}=5.960, p=0.0063 ; \operatorname{Sin} 3 \mathrm{a}: F_{(3,15)}=5.842, p=0.0104\right)$. $G$, Schematic model of transcriptional regulation of the $b d n f$ exon IV promoter following IA training. BDNF at training leads to an increase in $\mathrm{pCREB}$ and C/EBP $\beta$ binding at the bdnf exon $/ V$ promoter at $12 \mathrm{~h}$ after IA training, which correlates with increased transcription of $b d n f$ exon $I V$ as well as BDNF protein (Fig. 5). At $48 \mathrm{~h}$ after training, the binding of pCREB and C/EBP $\beta$ at the $b d n f$ exon IV promoter returns to baseline, while the binding of the inhibitors $\operatorname{Sin} 3 \mathrm{a}, \mathrm{MeC} 2$, and HDAC2 increases correlating with return to baseline of BDNF level. ${ }^{*} p<0.05,{ }^{* *} p<0.01$.

pression regulation via a positive autoregulatory feedback loop, which initiates, sustains, and ends the gene expressiondependent phase of consolidation. Interfering with translation or $\mathrm{BDNF}$ function at $24 \mathrm{~h}$ after training compromises the progression of consolidation and leads to memory decay. C/EBP $\beta$ is critical for the positive BDNF feedback loop: the induction of $\mathrm{C} / \mathrm{EBP} \beta$ requires $\mathrm{BDNF}$ at training and in turn $\mathrm{C} / \mathrm{EBP} \beta$ regu- 
lates the increase of BDNF expression during the lasting phase of consolidation.

The requirements for both de novo protein synthesis and $\mathrm{BDNF} / \mathrm{TrkB}$ in the hippocampus are crucial during the immediate phase after training to rapidly initiate memory consolidation, and a few minutes of BDNF/TrkB signaling and translation are sufficient to produce some memory retention that is maintained for a few days but then rapidly decays. Our anisomycin results extend the temporal window proposed in classical studies of a very rapid, initial phase of translation sufficient to promote memory consolidation (Squire and Davis, 1975). In most cases, in fact, these investigations did not continue the temporal analysis beyond the first day or two after training (Mark and Watts, 1971; Squire and Davis, 1975). Our findings also expand those of Medina's laboratory showing that anisomycin injected into the dorsal hippocampus at $12 \mathrm{~h}$ after step-down IA training but not at $9 \mathrm{~h}$ or $24 \mathrm{~h}$ post training disrupts memory retention tested at $7 \mathrm{~d}$ but not $2 \mathrm{~d}$ post training (Bekinschtein et al., 2007a, 2010). Moreover, similar temporal effects of translation inhibitors were reported in Aplysia californica neuronal cultures where a late sustained phase of translation was shown to be critical for the stabilization of long-term facilitation, indicating that a sustained requirement of translation is an evolutionarily conserved mechanism in long-term plasticity and memory (Miniaci et al., 2008). In summary our experiments extensively characterized the temporal profile of translation requirement occurring in the dorsal hippocampus during IA memory consolidation leading to the conclusion that de novo protein synthesis is essential for more than $1 \mathrm{~d}$ but less than $2 \mathrm{~d}$ after training.

Additionally, we showed that the requirement for translation to initiate memory consolidation follows a temporal progression similar to that of BDNF, although the difference between before and after training treatments is more dramatic with BDNF blockade than anisomycin. This difference may be due to the efficiency or concentration of blockers, but may also result from distinct target mechanisms of the anti-BDNF antibody versus those of anisomycin. Indeed, BDNF targets several signal transduction pathways, including those mediated by MAP kinase, Akt, and PLC $\gamma$, in addition to affecting translation and the mTOR pathway (Takei et al., 2004; Musumeci and Minichiello, 2011). Moreover, rapamycin, known to affect a subset of translation targeted by anisomycin as well as by BDNF, showed, in agreement with previous studies (Bekinschtein et al., 2007b), an even more dramatic difference with hippocampal pretraining versus posttraining injections. This suggests that the targets of rapamycin act very rapidly to initiate memory consolidation, which then progresses via rapamycin-independent mechanisms.

Both BDNF/TrkB and translation continue to be necessary for more than a day but less than two to complete the consolidation process. These data extend those of Medina's laboratory showing that blocking translation or BDNF in the dorsal hippocampus at $12 \mathrm{~h}$ after step-down IA training but not at $9 \mathrm{~h}$ or $24 \mathrm{~h}$ post training disrupts memory retention tested at $7 \mathrm{~d}$ but not $2 \mathrm{~d}$ post training (Bekinschtein et al., 2007a, 2010). The discrepancy between this study and our data for the effect of BDNF blockade at $24 \mathrm{~h}$ on memory retention at $7 \mathrm{~d}$ after training might be only apparent and likely due to the effect of retesting in their experiments.

The fact that hippocampal-mediated consolidation requires one entire day to complete is intriguing, as it suggests that circadian rhythms and sleep may significantly be involved (EckelMahan and Storm, 2009; Wang et al., 2011; Tononi and Cirelli, 2014).
Our results showed that the extended role of BDNF requires an upregulation of BDNF expression, which follows a temporal profile that parallels that of $\mathrm{C} / \mathrm{EBP} \beta$ induction, as $b \operatorname{dnf}$ exon $I V$ mRNA level is significantly elevated at 12 and $20 \mathrm{~h}$ but not at 30 min or $6 \mathrm{~h}$ post training and returns to baseline by $48 \mathrm{~h}$ after training. This increase in mRNA is paralleled by an increase in BDNF protein. As bdnf exon IV knockdown results in decreased levels of BDNF protein and disrupts memory consolidation, we conclude that in vivo bdnf exon $I V$ expression is necessary for long-term memory formation. Furthermore, we showed that $\mathrm{C} / \mathrm{EBP} \beta$ is a critical activator of BDNF expression because first, $\mathrm{C} / \mathrm{EBP} \beta$ binds to the promoter of the $b d n f$ exon $I V$ and this binding, like that of pCREB, significantly increases at $12 \mathrm{~h}$ after training and returns to baseline by $48 \mathrm{~h}$ post training when BDNF levels are also back to baseline. Second, C/EBP $\beta$ knockdown $5 \mathrm{~h}$ after training prevents BDNF increase and impairs long-term memory. Notably, this memory loss is fully rescued by rec$\mathrm{BDNF}$, indicating that BDNF is sufficient to rescue the $\mathrm{C} / \mathrm{EBP} \beta$ dependent mechanisms.

As $\mathrm{C} / \mathrm{EBP} \beta$ induction occurs downstream the BDNF requirement at training, which in turn controls the induction of BDNF expression, we conclude that a BDNF-C/EBP $\beta$-BDNF-positive autoregulatory loop in the dorsal hippocampus is necessary for initiating and sustaining the process of consolidation until completion when memory becomes fully resistant to hippocampal molecular interference. BDNF-induced BDNF synthesis regulated by CREB had been described in neuronal culture studies (Finkbeiner et al., 1997; Tao et al., 1998) and a feedback loop involving BDNF has been hypothesized to occur in the hippocampus in response to exercise (Vaynman et al., 2003).

To our knowledge our results are the first demonstration of a role of an autoregulatory-positive feedback loop of BDNF in long-term memory consolidation in vivo.

Administering BDNF after training does not rescue the amnesia caused by blocking BDNF before training, suggesting that BDNF-dependent initial changes, in addition to those downstream $\mathrm{C} / \mathrm{EBP} \beta$, are necessary for memory consolidation. However, blocking BDNF immediately after training permits BDNF to rescue memory decay. These results confirm that a few minutes of BDNF-induced changes following training are essential for the initiation of memory consolidation during which BDNF is required but not sufficient, and indicate that after this initiation BDNF is sufficient to sustain the entire process. We speculate that the changes occurring during the rapid, initial phase may include activity-dependent, post-translational modifications as well as translation of critical transcripts at synaptic sites.

Finally, we identified increased binding to the bdnf exon $I V$ promoter of transcriptional inhibitors, which are likely critical for turning off the autoregulatory-positive BDNF loop. MeCP2, a protein that is mutated in Rett syndrome and functions as a transcriptional repressor and/or global regulator of chromatin architecture (Chahrour et al., 2008; Skene et al., 2010; Cohen et al., 2011), together with Sin3a and HDAC2 significantly increase their binding to $b d n f$ exon $I V$ promoter at $48 \mathrm{~h}$ after training when BDNF mRNA is back to baseline, but not at $12 \mathrm{~h}$ after training when BDNF mRNA is increased as a result of training. Both HDAC2 and Sin3a have been previously shown to bind to bdnf exon $I V$ promoter both in vitro and in vivo and to downregulate $b d n f$ transcription in cortical neuronal cultures (Chen et al., 2003; Martinowich et al., 2003; Guan et al., 2009). Our results link and extend this knowledge to in vivo hippocampal mechanisms regulating memory consolidation, suggesting that the increased binding of MeCP2 and its corepressors Sin $3 \mathrm{a}$ and HDAC2 at the 
bdnf exon IV promoter, together with the decreased binding of pCREB and C/EBP $\beta$, are critical mechanisms by which the BDNF-positive autoregulation ends (Fig. $7 G$ ). Ending the positive autoregulation of BDNF expression is likely to be a critical step for an efficient consolidation, and its alteration may lead to functional impairments, as also suggested by the fact that overexpression of BDNF indeed leads to memory impairments (Cunha et al., 2009, 2010).

In summary, we propose that BDNF plays a persistent, critical role in the hippocampus for $>24 \mathrm{~h}$ after training through a positive autoregulatory feedback loop mediated by $\mathrm{C} / \mathrm{EBP} \beta$ and terminated by transcription inhibition mediated by $\mathrm{MeCP} 2$, HDAC2, and Sin3a. The sustained molecular mechanisms required for consolidation may facilitate memory trace reactivation during the first $24 \mathrm{~h}$ after training, which is suggested to promote hippocampal-neocortical interaction, thus leading to memory storage (Frankland and Bontempi, 2005). We speculate that a similar mechanism may support long-term plasticity responses in other brain regions and functions where BDNF plays a critical role.

This knowledge is important for better understanding how memories are consolidated and stored and formulating new working hypotheses about memory deficits or loss occurring in aging and diseases. It is also important for developing new strategies to either enhance or interfere with memory consolidation, hence combating cognitive impairments or disorders linked to pathogenic memories such as post-traumatic stress disorder and addiction.

\section{References}

Alberini CM (2009) Transcription factors in long-term memory and synaptic plasticity. Physiol Rev 89:121-145. CrossRef Medline

Alonso M, Vianna MR, Izquierdo I, Medina JH (2002) Signaling mechanisms mediating BDNF modulation of memory formation in vivo in the hippocampus. Cell Mol Neurobiol 22:663-674. CrossRef Medline

Bekinschtein P, Cammarota M, Igaz LM, Bevilaqua LR, Izquierdo I, Medina JH (2007a) Persistence of long-term memory storage requires a late protein synthesis- and BDNF- dependent phase in the hippocampus. Neuron 53:261-277. CrossRef Medline

Bekinschtein P, Katche C, Slipczuk LN, Igaz LM, Cammarota M, Izquierdo I, Medina JH (2007b) mTOR signaling in the hippocampus is necessary for memory formation. Neurobiol Learn Mem 87:303-307. CrossRef Medline

Bekinschtein P, Cammarota M, Katche C, Slipczuk L, Rossato JI, Goldin A, Izquierdo I, Medina JH (2008) BDNF is essential to promote persistence of long-term memory storage. Proc Natl Acad Sci U S A 105:2711-2716. CrossRef Medline

Bekinschtein P, Katche C, Slipczuk L, Gonzalez C, Dorman G, Cammarota M, Izquierdo I, Medina JH (2010) Persistence of long-term memory storage: new insights into its molecular signatures in the hippocampus and related structures. Neurotox Res 18:377-385. CrossRef Medline

Chahrour M, Jung SY, Shaw C, Zhou X, Wong ST, Qin J, Zoghbi HY (2008) $\mathrm{MeCP} 2$, a key contributor to neurological disease, activates and represses transcription. Science 320:1224-1229. CrossRef Medline

Chen DY, Stern SA, Garcia-Osta A, Saunier-Rebori B, Pollonini G, BambahMukku D, Blitzer RD, Alberini CM (2011) A critical role for IGF-II in memory consolidation and enhancement. Nature 469:491-497. CrossRef Medline

Chen DY, Bambah-Mukku D, Pollonini G, Alberini CM (2012) Glucocorticoid receptors recruit the CaMKIIalpha-BDNF-CREB pathways to mediate memory consolidation. Nat Neurosci 15:1707-1714. CrossRef Medline

Chen WG, Chang Q, Lin Y, Meissner A, West AE, Griffith EC, Jaenisch R, Greenberg ME (2003) Derepression of BDNF transcription involves calcium-dependent phosphorylation of MeCP2. Science 302:885-889. CrossRef Medline

Cohen S, Gabel HW, Hemberg M, Hutchinson AN, Sadacca LA, Ebert DH, Harmin DA, Greenberg RS, Verdine VK, Zhou Z, Wetsel WC, West AE,
Greenberg ME (2011) Genome-wide activity-dependent MeCP2 phosphorylation regulates nervous system development and function. Neuron 72:72-85. CrossRef Medline

Cunha C, Angelucci A, D'Antoni A, Dobrossy MD, Dunnett SB, Berardi N, Brambilla R (2009) Brain-derived neurotrophic factor (BDNF) overexpression in the forebrain results in learning and memory impairments. Neurobiol Dis 33:358-368. CrossRef Medline

Cunha C, Brambilla R, Thomas KL (2010) A simple role for BDNF in learning and memory? Front Mol Neurosci 3:1-14. CrossRef Medline

Dash PK, Orsi SA, Moore AN (2006) Spatial memory formation and memory-enhancing effect of glucose involves activation of the tuberous sclerosis complex-Mammalian target of rapamycin pathway. J Neurosci 26:8048-8056. CrossRef Medline

Davis HP, Squire LR (1984) Protein synthesis and memory: a review. Psychol Bull 96:518-559. CrossRef Medline

Dudai Y (2004) The neurobiology of consolidations, or, how stable is the engram? Annu Rev Psychol 55:51-86. CrossRef Medline

Eckel-Mahan KL, Storm DR (2009) Circadian rhythms and memory: not so simple as cogs and gears. EMBO Rep 10:584-591. CrossRef Medline

Finkbeiner S, Tavazoie SF, Maloratsky A, Jacobs KM, Harris KM, Greenberg ME (1997) CREB: a major mediator of neuronal neurotrophin responses. Neuron 19:1031-1047. CrossRef Medline

Frankland PW, Bontempi B (2005) The organization of recent and remote memories. Nat Rev Neurosci 6:119-130. CrossRef Medline

Guan JS, Haggarty SJ, Giacometti E, Dannenberg JH, Joseph N, Gao J, Nieland TJ, Zhou Y, Wang X, Mazitschek R, Bradner JE, DePinho RA, Jaenisch R, Tsai LH (2009) HDAC2 negatively regulates memory formation and synaptic plasticity. Nature 459:55-60. CrossRef Medline

Hong EJ, McCord AE, Greenberg ME (2008) A biological function for the neuronal activity-dependent component of Bdnf transcription in the development of cortical inhibition. Neuron 60:610-624. CrossRef Medline

Inda MC, Muravieva EV, Alberini CM (2011) Memory retrieval and the passage of time: from reconsolidation and strengthening to extinction. J Neurosci 31:1635-1643. CrossRef Medline

Katche C, Cammarota M, Medina JH (2013) Molecular signatures and mechanisms of long-lasting memory consolidation and storage. Neurobiol Learn Mem 106:40-47. CrossRef Medline

Lubin FD, Roth TL, Sweatt JD (2008) Epigenetic regulation of BDNF gene transcription in the consolidation of fear memory. J Neurosci 28:1057610586. CrossRef Medline

Mark RF, Watts ME (1971) Drug inhibition of memory formation in chickens. I. Long-term memory. Proc R Soc Lond B Biol Sci 178:439-454. CrossRef Medline

Martinowich K, Hattori D, Wu H, Fouse S, He F, Hu Y, Fan G, Sun YE (2003) DNA methylation-related chromatin remodeling in activity-dependent BDNF gene regulation. Science 302:890-893. CrossRef Medline

Medina JH, Bekinschtein P, Cammarota M, Izquierdo I (2008) Do memories consolidate to persist or do they persist to consolidate? Behav Brain Res 192:61-69. CrossRef Medline

Milekic MH, Brown SD, Castellini C, Alberini CM (2006) Persistent disruption of an established morphine conditioned place preference. J Neurosci 26:3010-3020. CrossRef Medline

Miniaci MC, Kim JH, Puthanveettil SV, Si K, Zhu H, Kandel ER, Bailey CH (2008) Sustained CPEB-dependent local protein synthesis is required to stabilize synaptic growth for persistence of long-term facilitation in Aplysia. Neuron 59:1024-1036. CrossRef Medline

Musumeci G, Minichiello L (2011) BDNF-TrkB signalling in fear learning: from genetics to neural networks. Rev Neurosci 22:303-315. CrossRef Medline

Pizzorusso T, Ratto GM, Putignano E, Maffei L (2000) Brain-derived neurotrophic factor causes cAMP response element-binding protein phosphorylation in absence of calcium increases in slices and cultured neurons from rat visual cortex. J Neurosci 20:2809-2816. Medline

Richter JD, Klann E (2009) Making synaptic plasticity and memory last: mechanisms of translational regulation. Genes Dev 23:1-11. CrossRef Medline

Shieh PB, Hu SC, Bobb K, Timmusk T, Ghosh A (1998) Identification of a signaling pathway involved in calcium regulation of BDNF expression. Neuron 20:727-740. CrossRef Medline

Skene PJ, Illingworth RS, Webb S, Kerr AR, James KD, Turner DJ, Andrews R, Bird AP (2010) Neuronal MeCP2 is expressed at near histone-octamer 
levels and globally alters the chromatin state. Mol Cell 37:457-468. CrossRef Medline

Slipczuk L, Bekinschtein P, Katche C, Cammarota M, Izquierdo I, Medina JH (2009) BDNF activates mTOR to regulate GluR1 expression required for memory formation. PLoS One 4:e6007. CrossRef Medline

Squire LR, Davis HP (1975) Cerebral protein synthesis inhibition and discrimination training: effect of extent and duration of inhibition. Behav Biol 13:49-57. CrossRef Medline

Takei N, Inamura N, Kawamura M, Namba H, Hara K, Yonezawa K, Nawa H (2004) Brain-derived neurotrophic factor induces mammalian target of rapamycin-dependent local activation of translation machinery and protein synthesis in neuronal dendrites. J Neurosci 24:9760-9769. CrossRef Medline

Takeuchi Y, Miyamoto E, Fukunaga K (2002) Analysis on the promoter region of exon IV brain-derived neurotrophic factor in NG108-15 cells. J Neurochem 83:67-79. CrossRef Medline

Tang SJ, Reis G, Kang H, Gingras AC, Sonenberg N, Schuman EM (2002) A rapamycin-sensitive signaling pathway contributes to long-term synaptic plasticity in the hippocampus. Proc Natl Acad Sci U S A 99:467-472. CrossRef Medline

Tao X, Finkbeiner S, Arnold DB, Shaywitz AJ, Greenberg ME (1998) Ca2+ influx regulates BDNF transcription by a CREB family transcription factor-dependent mechanism. Neuron 20:709-726. CrossRef Medline

Taubenfeld SM, Milekic MH, Monti B, Alberini CM (2001a) The consoli- dation of new but not reactivated memory requires hippocampal C/EBPbeta. Nat Neurosci 4:813-818. CrossRef Medline

Taubenfeld SM, Wiig KA, Monti B, Dolan B, Pollonini G, Alberini CM (2001b) Fornix-dependent induction of hippocampal CCAAT enhancer-binding protein [beta] and [delta] Co-localizes with phosphorylated cAMP response element-binding protein and accompanies long-term memory consolidation. J Neurosci 21:84-91. Medline

Tononi G, Cirelli C (2014) Sleep and the price of plasticity: from synaptic and cellular homeostasis to memory consolidation and integration. Neuron 81:12-34. CrossRef Medline

Tsankova NM, Kumar A, Nestler EJ (2004) Histone modifications at gene promoter regions in rat hippocampus after acute and chronic electroconvulsive seizures. J Neurosci 24:5603-5610. CrossRef Medline

van Dijk MA, Rodenburg RJ, Holthuizen P, Sussenbach JS (1992) The liverspecific promoter of the human insulin-like growth factor II gene is activated by CCAAT/enhancer binding protein (C/EBP). Nucleic Acids Res 20:3099-3104. CrossRef Medline

Vaynman S, Ying Z, Gomez-Pinilla F (2003) Interplay between brainderived neurotrophic factor and signal transduction modulators in the regulation of the effects of exercise on synaptic-plasticity. Neuroscience 122:647-657. CrossRef Medline

Wang G, Grone B, Colas D, Appelbaum L, Mourrain P (2011) Synaptic plasticity in sleep: learning, homeostasis and disease. Trends Neurosci 34:452-463. CrossRef Medline 